\title{
CFTR Modulators: Shedding Light on Precision Medicine for Cystic Fibrosis
}

\author{
Miquéias Lopes-Pacheco* \\ Institute of Biophysics Carlos Chagas Filho, Federal University of Rio de Janeiro, Rio de Janeiro, Brazil
}

\section{OPEN ACCESS}

Edited by: Frederic Becq,

University of Poitiers, France

Reviewed by:

Valerie Chappe,

Dalhousie University, Canada

Paola Vergani,

University College London, UK

${ }^{*}$ Correspondence: Miquéias Lopes-Pacheco mlopes0811@gmail.com miqueiaslopes@biof.ufrj.br

Specialty section:

This article was submitted to Pharmacology of lon Channels and Channelopathies, a section of the journal

Frontiers in Pharmacology

Received: 23 May 2016

Accepted: 11 August 2016 Published: 05 September 2016

Citation: Lopes-Pacheco M (2016) CFTR Modulators: Shedding Light on Precision Medicine for Cystic Fibrosis.

Front. Pharmacol. 7:275 doi: 10.3389/fphar.2016.00275
Cystic fibrosis (CF) is the most common life-threatening monogenic disease afflicting Caucasian people. It affects the respiratory, gastrointestinal, glandular and reproductive systems. The major cause of morbidity and mortality in CF is the respiratory disorder caused by a vicious cycle of obstruction of the airways, inflammation and infection that leads to epithelial damage, tissue remodeling and end-stage lung disease. Over the past decades, life expectancy of CF patients has increased due to early diagnosis and improved treatments; however, these patients still present limited quality of life. Many attempts have been made to rescue CF transmembrane conductance regulator (CFTR) expression, function and stability, thereby overcoming the molecular basis of CF. Gene and protein variances caused by CFTR mutants lead to different CF phenotypes, which then require different treatments to quell the patients' debilitating symptoms. In order to seek better approaches to treat CF patients and maximize therapeutic effects, CFTR mutants have been stratified into six groups (although several of these mutations present pleiotropic defects). The research with CFTR modulators (read-through agents, correctors, potentiators, stabilizers and amplifiers) has achieved remarkable progress, and these drugs are translating into pharmaceuticals and personalized treatments for CF patients. This review summarizes the main molecular and clinical features of CF, emphasizes the latest clinical trials using CFTR modulators, sheds light on the molecular mechanisms underlying these new and emerging treatments, and discusses the major breakthroughs and challenges to treating all CF patients.

Keywords: CFTR, cystic fibrosis, protein misfolding, intracellular trafficking, proteostasis network, personalized medicine, ABC transporters

Abbreviations: ABC, ATP-binding cassette; AHSA1, activator of $90 \mathrm{kDa}$ Hsp ATPase homolog 1; ATP, adenosine triphosphate; cAMP, cyclic adenosine monophosphate; CAL, CFTR-associated ligand; CF, cystic fibrosis; CFBE, CF bronchial epithelial; CFTR, CF transmembrane conductance regulator; CHIP, carboxyl terminus of Hsc70-interacting protein; EPAC, exchange protein directly activated by cAMP; ER, endoplasmic reticulum; EMA, European Medicines Agency; ENaC, epithelial $\mathrm{Na}^{+}$channel; ERAD, ER-associated degradation; FDA, Food and Drug Administration; $\mathrm{FEV}_{1}$, forced expiratory volume in $1 \mathrm{~s}$; HBE, human bronchial epithelial; HDAC, histone deacetylase; HGF, hepatocyte growth factor; Hsc, heat shock cognate; Hsp, heat shock protein; HTS, high-throughput screening; NBD, nucleotide-binding domain; NHERF-1, $\mathrm{Na}^{+} / \mathrm{H}^{+}$ exchanger regulatory factor; PKA, protein kinase A; PKC, protein kinase C; PM, plasma membrane; PPQC, peripheral protein quality control; RD, regulatory domain; SNARE, soluble $N$-ethylmaleimide-sensitive factor attachment protein receptor; SUMO, small ubiquitin-like modifier; STX, syntaxin; TMD, transmembrane domain; VCP, vasolin-containing protein; VIP, vasoactive intestinal peptide; $w t$, wild type. 


\section{INTRODUCTION}

Mutations in the cystic fibrosis transmembrane conductance regulator (CFTR) gene cause cystic fibrosis (CF) - the most common life-limiting autosomal recessive inherited disorder in Caucasian people. The mutated gene translates into a defective CFTR protein with loss-of-activity (Kerem et al., 1989; Riordan et al., 1989). CFTR encodes an anion channel expressed in several cell types that: (1) transports chloride across the apical membrane; (2) modulates the activity of other ion channels, thereby regulating fluid and electrolyte balance in the mucosal membranes; and (3) secretes bicarbonate, which is crucial for $\mathrm{pH}$ regulation, host defense and protection against noxious stimuli (Gadsby et al., 2006; Gentzsch et al., 2010; Gustafsson et al., 2012). As a protein of the ATP-binding cassette (ABC) family, CFTR is comprised of two transmembrane domains (TMDs), two nucleotide-binding domains (NBDs) and a unique regulatory domain (RD) (Gadsby et al., 2006) (Figure 1). Cyclic AMP (cAMP)-dependent protein kinase A (PKA), protein kinase $\mathrm{C}(\mathrm{PKC})$ and ATP control its activity (Winter and Welsh, 1997; Chappe et al., 2003). The most prevalent CFTR mutation was discovered almost 30 years ago; it was the deletion of a phenylalanine at position 508 ( $\Delta$ F508) (Kerem et al., 1989; Riordan et al., 1989), which affects $\sim 80 \%$ of CF patients worldwide (Bobadilla et al., 2002; Sosnay et al., 2013). The mutation $\Delta$ F508 reduces thermal and kinetic stability of NBD1 and precludes interdomain interactions (Serohijos et al., 2008; Mendoza et al., 2012). Hence, the endoplasmic reticulum (ER) retains misfolded $\triangle$ F508-CFTR, which forms only a partially glycosylated protein, and the proteasome promptly degrades it (Cheng et al., 1990; Jensen et al., 1995).

CF is a systemic disease that affects $\sim 85,000$ people and presents heterogeneous distribution globally (Bobadilla et al., 2002; Sosnay et al., 2013) (Figure 2, Table 1). According to the latest registry reports, 38,985 CF patients are in Europe (European Cystic Fibrosis Society [ECFS], 2016), 28,676 in the United States (Cystic Fibrosis Foundation [CFF], 2015), 4,128 in Canada (Cystic Fibrosis Canada [CFC], 2016), 3,294 in Australia (Cystic Fibrosis Federation Australia [CFFA], 2016) and 3,511 in Brazil (Brazilian Cystic Fibrosis Study Group [GBEFC], 2016) (Figure 3). The major cause of morbidity and mortality in $\mathrm{CF}$ is the respiratory disorder caused by the lack of CFTR at the plasma membrane (PM) (Moskowitz et al., 2008), which decreases the anion permeability in airway cells and leads to a progressive pathophysiological cascade (Figure 4): (1) A faulty conductance of other ions, such as excessive sodium transport mediated by epithelial $\mathrm{Na}^{+}$ channel $(\mathrm{ENaC})$, since it is negatively regulated by CFTR (Kunzelmann et al., 1995; Gentzsch et al., 2010). Controversially, some reports have shown that CFTR loss-of-activity reduces chloride conductance without increasing sodium absorption in CF epithelia (Chen et al., 2010; Itani et al., 2011). (2) The imbalance of ion regulation depletes water content and/or decreases $\mathrm{pH}$ in the airway surface liquid (Tarran et al., 2005; Tang et al., 2016). (3) Dehydration and/or acidification of epithelial lining, as well as increased mucin polymer cross-links, raise the amount and viscosity of mucus in gel phase (Tarran et al., 2005; Yuan et al., 2015; Shah et al., 2016; Tang et al., 2016), making the mucus tenacious and difficult to remove by ciliary beating. (4) Accumulation of mucus leads to obstruction of the airways, inflammation and bronchiectasis. (5) Frequently, pathogens colonize the airways and increase the recruitment of inflammatory cells (Lyczak et al., 2002; Bhatt, 2013). Furthermore, oxygen depletion below the sputumair interface favors biofilm formation (Worlitzsch et al., 2002; Cowley et al., 2015). (6) The destruction of airway and lung parenchyma epithelial cells causes tissue remodeling, reduction of gas exchange area and impairment of lung function. (7) As the disease progresses, the patient succumbs to death due to respiratory failure.

In addition to the substantial impact of CFTR dysfunction in the upper and lower respiratory tract, CF patients also experience clinical manifestations related to the reproductive, gastrointestinal and glandular systems (Table 2). Male infertility is present in $98 \%$ of cases, and about $85 \%$ of CF patients have pancreatic insufficiency, often associated to malnutrition.

Salt loss syndrome also affects CF patients, since chloride reabsorption via CFTR in the sweat glands is compromised, increasing chloride elimination $\left(>60 \mathrm{mmol} . \mathrm{L}^{-1}\right)$, as well as of other ions. In fact, the iontophoretic sweat test is considered the 'gold standard' for the diagnosis of CF. It precedes only the confirmation of a diagnosis by genetic testing (Lyczak et al., 2002; Farrell et al., 2008; Castellani et al., 2016). In addition, sweat chloride measurement is a biomarker of CFTR activity and response for new treatments (Accurso et al., 2014; Collaco et al., 2016).

\section{LIFE EXPECTANCY IN CYSTIC FIBROSIS}

Multifactorial improvements have increased the survival of CF patients (Figure 5): early diagnosis, genotype-phenotype detection, nutritional support, more efficient and effective pulmonary interventions, multidisciplinary professional monitoring, establishment of CF specialist centers and, most recently, the development of precision medicine (Farrell et al., 2008; Cohen-Cymberknoh et al., 2011; Smyth et al., 2014; Quon and Rowe, 2016).

In the last decades, many countries have adopted newborn screening programs. Newborns are diagnosed through the measurement of immunoreactive trypsinogen. This early diagnosis and the confirmation of the disease through the sweat test are important for a better prognosis (Farrell et al., 2008; Djik and Fitzgerald, 2012; Castellani et al., 2016). Thereafter, identifying which are the mutations in the CFTR gene is crucial, since different ethnic or regional populations can have a different spectrum of CFTR variants, each leading to different degrees of disease severity (Moskowitz et al., 2008; Pique et al., 2016; Schrijver et al., 2016).

A multidisciplinary team of health professionals should perform periodic monitoring of the disease progression and make any necessary adjustments in treatments in order for patients to achieve the best clinical outcomes 


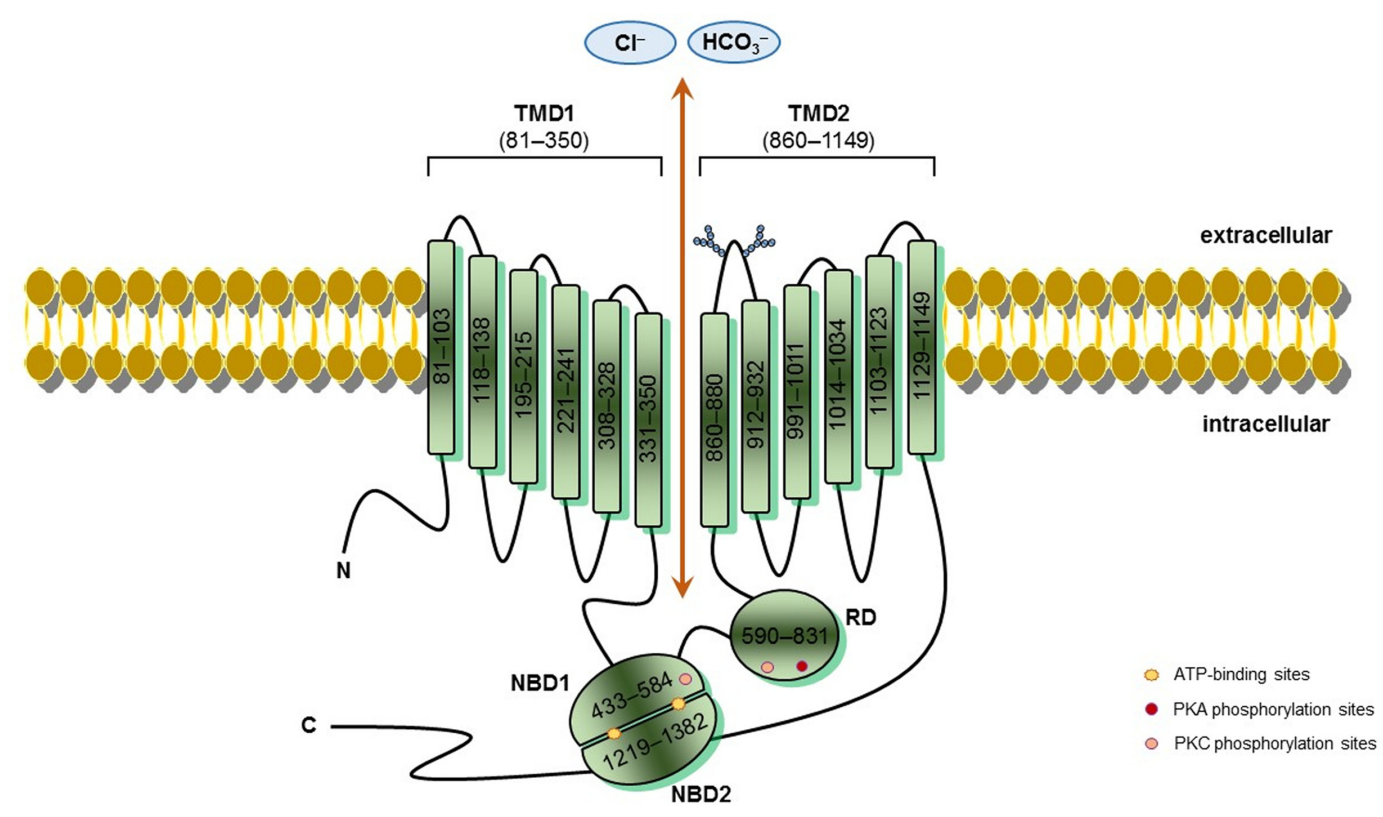

FIGURE 1 | CFTR schematic structure - Cystic fibrosis transmembrane conductance regulator (CFTR) is a 1,480-amino acids protein inserted into the cell surface. CFTR possesses five domains: two transmembrane domains (TMD1/2), containing six hydrophobic alpha-helices, which cross the cell surface lipid bilayer, and are joined by two intracellular loops and three extracellular loops, and with glycosylated residues linked in the extracellular loop 4 (N894, N900); two nucleotide-binding domains (NBD1/2) with highly conserved sequenced for ATP-binding, where occur hydrolysis; and one regulatory domain (RD) with multiple phosphorylation sites. CFTR channel open when protein kinase A (PKA) and protein kinase C (PKC) phosphorylate RD and ATPs bind to side chain charged amino acids in NBDs, thereby activating CFTR function. TMDs form the gate where occurs chloride conductance. The positions denoted into the boxes correspond to the first and last amino acid of each fragment and CFTR sequence was obtained in the Cystic Fibrosis Mutation Database (CFTR1 database; http://www.genet.sickkids.on.ca/Home.html).

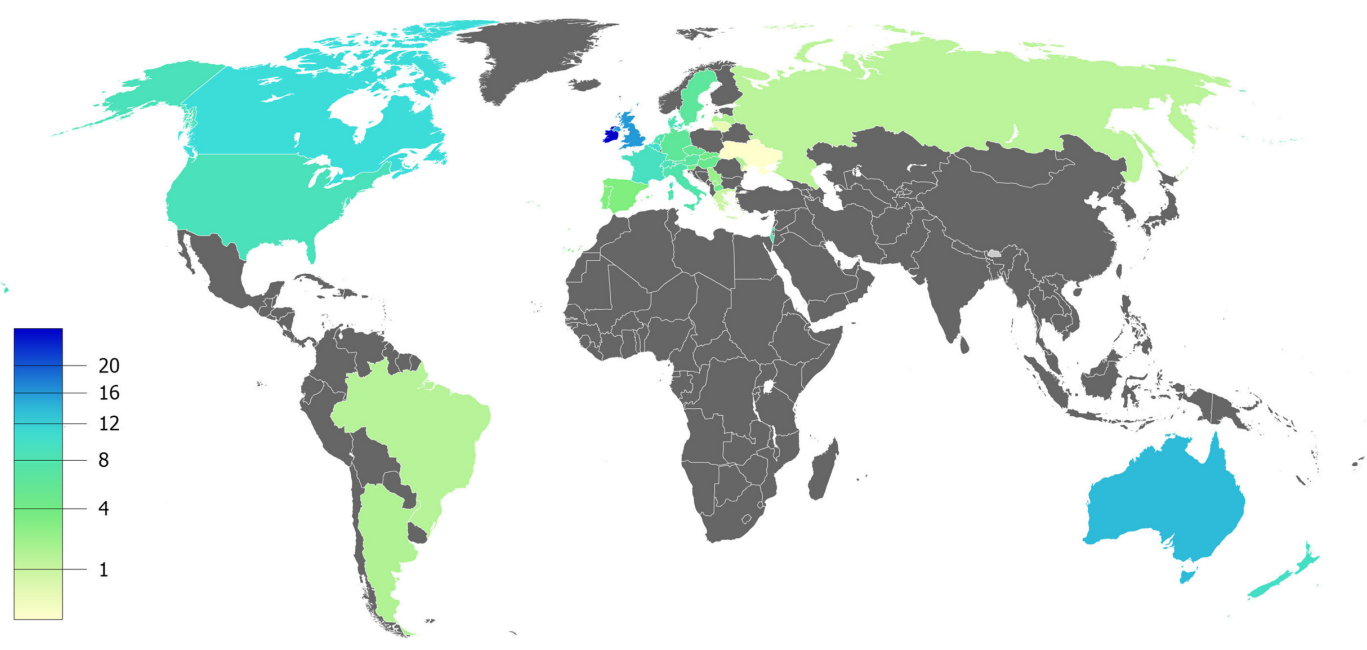

FIGURE 2 | Estimated prevalence of cystic fibrosis per 100,000 habitants - Data compiled from the latest registry reports of Europe (European Cystic Fibrosis Society [ECFS], 2016), United States (Cystic Fibrosis Foundation [CFF], 2015), Canada (Cystic Fibrosis Canada [CFC], 2016), Australia (Cystic Fibrosis Federation Australia [CFFA], 2016) and Brazil (Brazilian Cystic Fibrosis Study Group [GBEFC], 2016).

(Cohen-Cymberknoh et al., 2011; Smyth et al., 2014). CF patients show weight loss and impaired growth due to pancreatic insufficiency and intestinal malabsorption. Supplementations with pancreatic enzymes and fat-soluble vitamins have improved their nutritional status (Feranchak et al., 1999; Kalnins and Wilschanski, 2012). Lung injuries are the most common clinical characteristic due to mucociliary clearance impairment in the airways. Production of very viscous mucus impairs the ciliary 
TABLE 1 | Top 10 countries with the highest number of CF patients.

\begin{tabular}{lcc}
\hline & Registered patients & Per 100,000 habitants \\
\hline $1^{\circ}$ & United States & Ireland \\
$2^{\circ}$ & United Kingdom & United Kingdom \\
$3^{\circ}$ & France & Australia \\
$4^{\circ}$ & Germany & Canada \\
$5^{\circ}$ & Italy & Belgium \\
$6^{\circ}$ & Canada & New Zealand \\
$7^{\circ}$ & Brazil & France \\
$8^{\circ}$ & Australia & United States \\
$9^{\circ}$ & Russia & Switzerland \\
$10^{\circ}$ & Spain & Denmark \\
\hline
\end{tabular}

beating, and treatments with mucolytic (e.g., dornase-alpha) (Fuchs et al., 1994) or hydrator (e.g., mannitol, hypertonic saline) (Elkins et al., 2006; Bilton et al., 2011) are helpful in eliminating the retained mucus. Antibiotic therapy is also essential, since the mucus becomes trapped in the respiratory tract, causing recurrent and persistent infections by a group of opportunistic pathogens: Burkholderia cepacia, Haemophilus influenzae, Pseudomonas aeruginosa (hallmark of CF), Staphylococcus aureus and Stenotrophomonas maltophilia (Lyczak et al., 2002; Worlitzsch et al., 2002; Bonestroo et al., 2010; Bhatt, 2013). It is noteworthy that during infection by $P$. aeruginosa, the bacterial population can segregate and evolve differently according to the lung microenvironment, leading to differences in the bacterial characteristics, such as nutritional requirements, defense and microbial resistance. This may explain, partly, why this pathogen is so prevalent and difficult to eradicate from CF patient lungs (Jorth et al., 2015; LaFayette et al., 2015).

Non-pharmacological treatments, such as aerobic exercise, physiotherapy, feeding and physiological supports, are also important to high-quality care and better outcomes (CohenCymberknoh et al., 2011; Smyth et al., 2014). As the disease progresses, patients require continuous therapy with oxygen, and in the end-stage lung disease, the only alternative is lung transplantation, which still presents a high risk of cellular rejection (Adler et al., 2009; Calabrese et al., 2015).

Over the past decades, all the above-mentioned improvements have lengthened the life expectancy of CF patients. In 1960, CF patients only lived through childhood. Nowaday, they live to see their forties (Figure 5), and those born more recently are expected to make it to their fifties (Cohen-Cymberknoh et al., 2011; MacKenzie et al., 2014; Burgel et al., 2015). However, CF patients still present even more reduced life expectancy - between 20 and 30 years - in some regions of the world, including Brazil and the African continent (Marson et al., 2015; Stewart and Pepper, 2016).

Several new complications associated with increased survival (Table 2), which were rare or not previously observed, pose new challenges for CF scholars. CF-related diabetes, metabolic bone disease and multidrug-resistant pulmonary pathogens are some comorbidities in older CF patients (Plant et al., 2013). Although still uncommon, adult CF patients have a higher
A

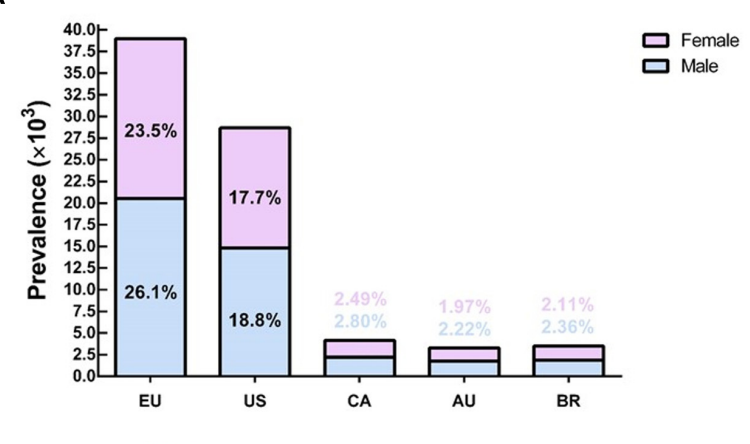

B

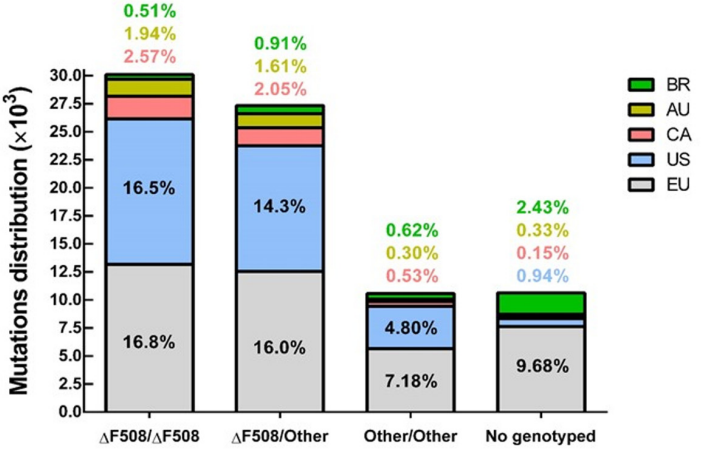

C

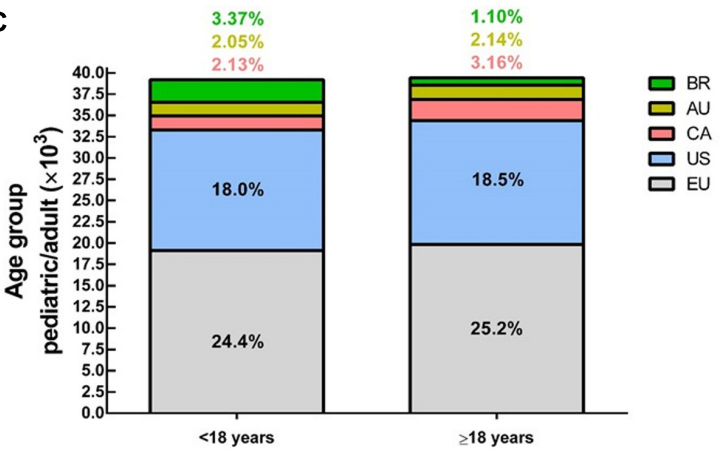

FIGURE 3 | Demography of cystic fibrosis in a sample of 78,627 patients in different countries or demographic regions - (A) Prevalence by gender: average of $52 \%$ male and $48 \%$ female. (B) Within the sample group, $86 \%$ have been genotyped and approximately $38 \%$ are $\Delta$ F508-homozygous, $35 \% \Delta$ F508-heterozygous and $13 \%$ bearing other CFTR (cystic fibrosis transmembrane conductance regulator) mutants in both alleles. (C) About $50 \%$ of patients are under 18 years and $50 \%$ are 18 years or older. Data compiled from the latest registry reports of Europe (EU;

European Cystic Fibrosis Society [ECFS], 2016), United States (US; Cystic Fibrosis Foundation [CFF], 2015), Canada (CA; Cystic Fibrosis Canada [CFC], 2016), Australia (AU; Cystic Fibrosis Federation Australia [CFFA], 2016) and Brazil (BR; Brazilian Cystic Fibrosis Study Group [GBEFC], 2016).

risk of gastrointestinal cancer compared to an age-matched non-CF population (Maisonneuve et al., 2013), which may be explained by the fact that CFTR is a tumor suppressor gene (Than et al., 2016). Another severe complication is the allergic bronchopulmonary aspergillosis, which is correlated to accelerated decline of lung function in adult CF patients (Armstead et al., 2014). 


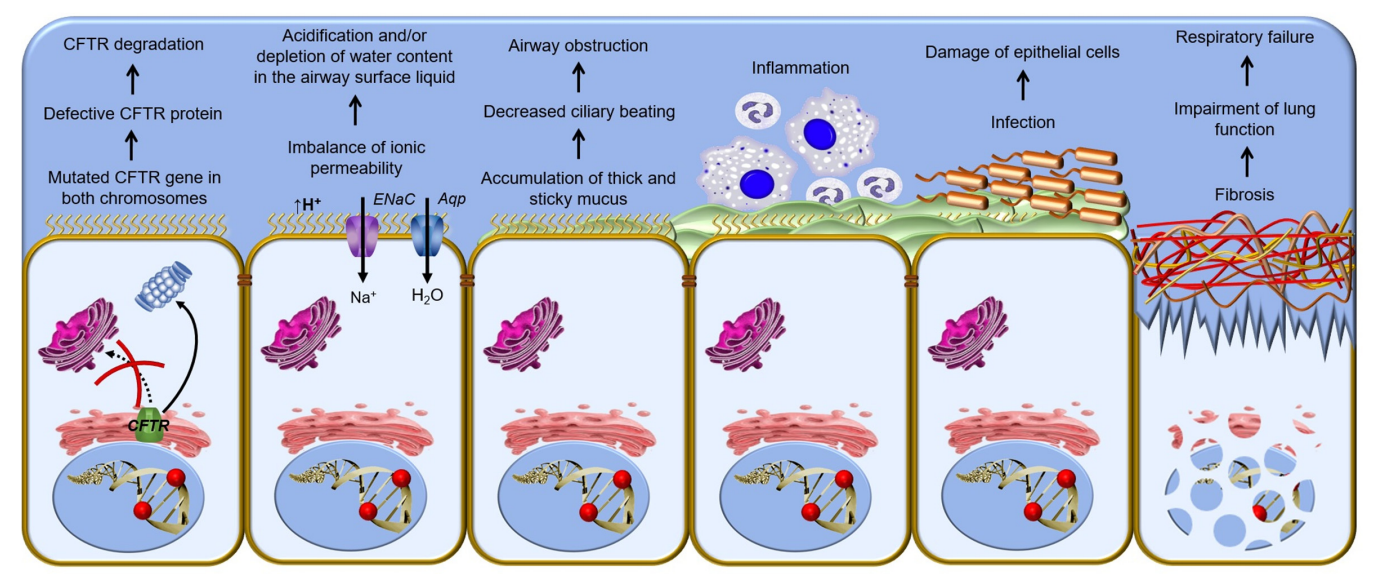

FIGURE 4 | Pathophysiological cascade of respiratory disorder in cystic fibrosis - Cellular mechanism of cystic fibrosis begins with the defective CFTR (cystic fibrosis transmembrane conductance regulator) gene and shortage of CFTR channel at the plasma membrane. A vicious cycle of airways obstruction, inflammation and infection leads to epithelial damage, lung remodeling and end-stage lung disease. ENaC, epithelial $\mathrm{Na}^{+}$channel; Aqp, aquaporin.

TABLE 2 | Approximate age of onset of CF clinical manifestations and comorbidities.

\begin{tabular}{|c|c|c|c|c|}
\hline & $\begin{array}{l}\text { Upper and lower respiratory } \\
\text { tract }\end{array}$ & $\begin{array}{l}\text { Gastrointestinal and } \\
\text { hepatobiliary systems }\end{array}$ & $\begin{array}{l}\text { Endocrine and reproductive } \\
\text { systems }\end{array}$ & $\begin{array}{l}\text { Salt-wasting syndrome and } \\
\text { others }\end{array}$ \\
\hline $\begin{array}{l}\text { Babyhood and } \\
\text { childhood }\end{array}$ & $\begin{array}{l}\text { Chronic cough } \\
\text { Sputum overproduction } \\
\text { Tenacious mucus } \\
\text { Airway obstruction } \\
\text { Recurrent and persistent } \\
\text { pneumonia or lung infections } \\
\text { Bronchiectasis } \\
\text { Nasal polyps/sinus disease }\end{array}$ & $\begin{array}{l}\text { Meconium ileus } \\
\text { Steatorrhea } \\
\text { Deficiency of fat-soluble } \\
\text { vitamins } \\
\text { Intussusception } \\
\text { Recurrent pancreatitis } \\
\text { Pancreatic insufficiency }\end{array}$ & $\begin{array}{l}\text { Absence of the vas deferens } \\
\text { Impaired growth }\end{array}$ & $\begin{array}{l}\text { Salty sweat } \\
\text { Mucosal dehydration } \\
\text { Hypochloremia } \\
\text { Hyponatremia } \\
\text { Hypokalemia } \\
\text { Digital clubbing }\end{array}$ \\
\hline $\begin{array}{l}\text { Adolescence and } \\
\text { adulthood }\end{array}$ & $\begin{array}{l}\text { Atelectasis } \\
\text { Impaired pulmonary function } \\
\text { Hemoptysis } \\
\text { Chronic infection with } \\
\text { multidrug-resistant pathogens } \\
\text { Allergic bronchopulmonary } \\
\text { aspergillosis } \\
\text { Pneumothorax } \\
\text { Respiratory failure }\end{array}$ & $\begin{array}{l}\text { Biliary fibrosis/cirrhosis } \\
\text { Hepatic steatosis } \\
\text { Gastroesophageal reflux } \\
\text { Distal intestinal obstruction } \\
\text { syndrome } \\
\text { Digestive tract cancer }\end{array}$ & $\begin{array}{l}\text { Delayed puberty } \\
\text { Oligomenorrhea } \\
\text { Reduced fertility in women } \\
\text { Obstructive azoospermia in } \\
\text { males } \\
\text { CF-related diabetes mellitus } \\
\text { Reduced bone mineral } \\
\text { density/osteoporosis }\end{array}$ & $\begin{array}{l}\text { Arthritis/vasculitis } \\
\text { Nephrolithiasis } \\
\text { Chronic kidney disease } \\
\text { Anxiety/depression }\end{array}$ \\
\hline
\end{tabular}

Please note that the clinical signs and symptoms in an approximate age of onset do not exclude the possibility of these arose from early or late manner.

Despite the increase in life expectancy, CF patients still present a limited quality of life due to the high costs and the burden of treatments needed. In particular, CF patients living in developing countries tend to have worse clinical outcomes compared to those who live in developed countries, since lower-income countries have scarce financial resources to optimize therapies, including the application of precision medicine (Cohen-Cymberknoh et al., 2016). Precision medicine (or personalized treatment) is a new approach that takes into account the genetic variances of each individual. Therefore, CF patients with different CFTR mutations may require different treatments to quell their debilitating symptoms (Quon and Rowe, 2016). The knowledge obtained about the molecular scenario in which CFTR mutants are degraded has contributed to understanding the different defects caused by different mutants, and thus to developing drugs that rectify the primary defect of specific mutations.

\section{A PROTEOSTASIS NETWORK ENGAGED IN CFTR DEGRADATION}

CFTR biogenesis is a cellular process that involves several steps: post-transcriptional splicing, protein translation, folding at the ER, glycosylation at the Golgi apparatus, trafficking to the apical membrane, endosomal recycling and retrieval. The cellular and transcellular protein trafficking involves multiple quality control systems to compensate the limited fidelity of each system. Therefore, a protein homeostasis (proteostasis) network carefully checks CFTR maturation pathway (Balch et al., 2011). Among the quality control systems, ubiquitin-proteasome pathway destroys the largest fraction of misfolded CFTR (Cheng et al., 1990; Jensen et al., 1995), and aggresomes degrade by autophagy CFTR molecules that proteasomes cannot degrade (Kawaguchi et al., 2003; Luciani et al., 2010). In addition, 


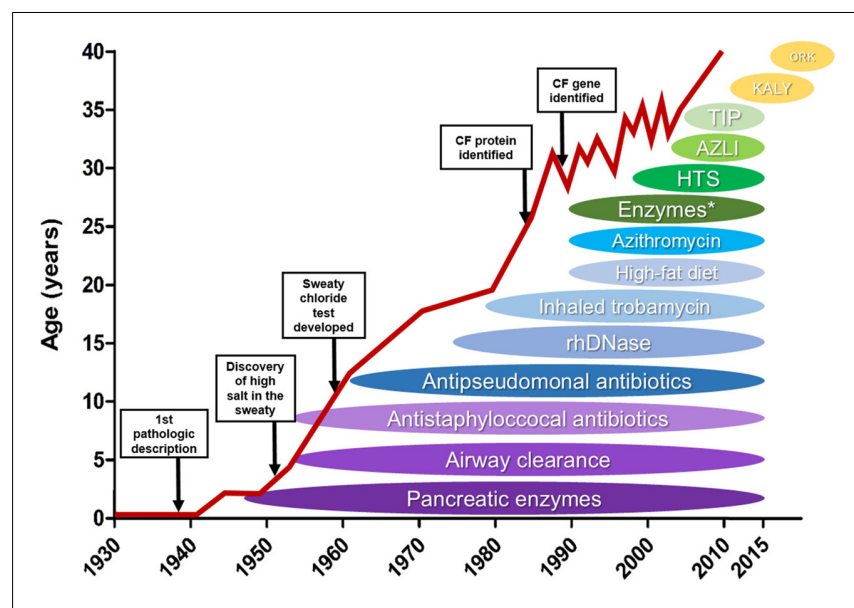

FIGURE 5 | Effect of novel therapies on life expectancy of cystic fibrosis patients - Schematic illustration of how the discovery and introduction of novel cystic fibrosis (CF) treatments have influenced the patients' survival over the decades. HTS: high throughput screening, AZLI, aztreonam for inhalation solution; TIP, tobramycin inhalation solution; KALY, Kalydeco $^{\text {TM}}$; ORK, Orkambi ${ }^{\mathrm{TM}}$. *enteric-coated pancreatic enzymes. (Reproduced and adapted with permission of European Respiratory Society@: The European Lung White Book Respiratory Health and Disease in Europe, $2^{\text {nd }}$ Ed. (C) 2013 European Respiratory Society, Sheffield, UK. Print ISBN: 978-1-84984-042-2, Online ISBN: 978-1-84984-043-9).

lysosomes eliminate non-native CFTR that escapes from ERassociated degradation (ERAD) (Sharma et al., 2004; Glozman et al., 2009; Okiyoneda et al., 2010). The mutant $\Delta$ F508 fails to achieve the native conformation and ERAD machinery arrests CFTR, thereby precluding the protein from being delivered to the PM (Cheng et al., 1990; Jensen et al., 1995).

CFTR folding is facilitated by many molecular chaperones and co-chaperones, which form a CFTR interactome; however, unstable and misfolded CFTR remains bound to chaperones, promoting premature degradation of CFTR (Balch et al., 2011; Amaral and Farinha, 2013; Kim et al., 2013; Pankow et al., 2015) (Figure 6). The heat shock protein (Hsp)27 (or HspB1) binds $\Delta$ F508 with small ubiquitin-like modifier (SUMO)-2, directing it to be degraded via SUMOylation (Ahner et al., 2013; Gong et al., 2016). Hsp27 also prevents protein aggregation during stress (Ahner et al., 2007). Hsp40 (or DnaJ) sequesters misfolded CFTR for ERAD and it works as a co-chaperone for Hsp70 (Meacham et al., 1999; Farinha et al., 2002; Kakoi et al., 2013). Hsp70 is a core ER chaperone and its prolonged association with CFTR mutant results in CFTR ubiquitination and degradation by the 26S proteasome (Yang et al., 1993; Jensen et al., 1995; Meacham et al., 2001; Sun et al., 2006). Hsp70 connects to heat shock cognate (Hsc)70, forming the first ER checkpoint that retains the mutant $\Delta \mathrm{F} 508$. Hsc70 couples to its cochaperone, the carboxyl terminus of Hsc70-interacting protein (CHIP), and leads CFTR mutant to degradation (Meacham et al., 1999, 2001; Farinha and Amaral, 2005). Hsp90 helps wild type (wt)-CFTR to achieve the complete folding, but it also forms a 'chaperones trap' with Hsp40/Hsp70 that targets $\Delta$ F508 for proteasome degradation (Wang et al., 2006; Ahner et al., 2007; Koulov et al., 2010; Coppinger et al., 2012). The ATPase activity of $\mathrm{Hsp} 90$ is regulated by its co-chaperone, the activator of $90 \mathrm{kDa}$ Hsp APTase homolog 1 (AHSA1 or Aha1) (Wang et al., 2006; Koulov et al., 2010). Calnexin is an ER transmembrane chaperone that acts as second checkpoint, assessing CFTR folding status and sending the misfolded protein for degradation (Farinha and Amaral, 2005; Okiyoneda et al., 2008).

In addition to the molecular chaperones, inhibition of the histone deacetylase (HDAC) (Hutt et al., 2010; Pankow et al., 2015) or the vasolin-containing protein (VCP or p97) (Vij et al., 2006) rescues the trafficking and gating of $\triangle$ F508-CFTR. VCP (Boyault et al., 2006) and HDAC6 (Kawaguchi et al., 2003) translocate misfolded proteins to proteasomes and aggresomes, respectively. VCP is associated to ubiquitinated CFTR, whereas derlin-1 recognizes misfolded, non-ubiquitinated CFTR and initiates its dislocation and degradation in the early course of CFTR biogenesis (Sun et al., 2006). The CFTR-associated ligand $(\mathrm{CAL})$ is a PDZ domain-containing protein, located primarily at Golgi apparatus, which modulates surface expression of CFTR (Cheng et al., 2002). CAL forms a complex with syntaxin (STX)6 that promotes CFTR degradation in lysosomes (Cheng et al., 2010; Cheng and Guggino, 2013). STX8 is an endosomal protein that impairs CFTR trafficking and inhibits its chloride channel activity by soluble $N$-ethylmaleimide-sensitive factor attachment protein receptor (SNARE) machinery (Bilan et al., 2004). Vasoactive intestinal peptide (VIP) is a neuropeptide that promotes interaction between CFTR and $\mathrm{Na}^{+} / \mathrm{H}^{+}$exchanger regulatory factor 1 (NHERF-1) (Alshafie et al., 2014). NHERF1 is a CFTR-binding protein that regulates CFTR distribution and function at the PM (Guerra et al., 2005; Kwon et al., 2007; Favia et al., 2010). Moreover, a system of peripheral proteins quality control (PPQC) removes CFTR from the PM if that is recognized as improperly folded (Okiyoneda et al., 2010).

In healthy conditions, the proteostasis network maintains a healthful proteome by integrating transcription, translation, folding and trafficking systems. However, a decline in the cellular proteostasis capacity occurs with aging, as well as protein misfolding/aggregation disorders cause an imbalance in the expression and/or binding of proteostasis components with client proteins, which accentuates the importance of a healthy quality control system (Balch et al., 2011; Kim et al., 2013; Villella et al., 2013). CFTR protein must fold into well-defined threedimensional structure to attain stability and functionality (Balch et al., 2011; Kim et al., 2013). The protein lack or its incorrect folding prevents CFTR from performing its normal function and cells may respond to that by maintaining an activated heat shock response and leading to a maladaptive stress response. This effort to neutralize misfolding protein accumulation causes an additional stress to cells that may result in the exacerbation of disease symptoms. These findings were observed in cell lines and primary epithelium from CF and other misfolding protein diseases: alpha-1-antitrypsin, Alzheimer's disease and NiemannPick type C1 disease (Roth et al., 2014). Another important determinant in inherited disorders is that the disease severity depends of the genetic background of each individual and not 


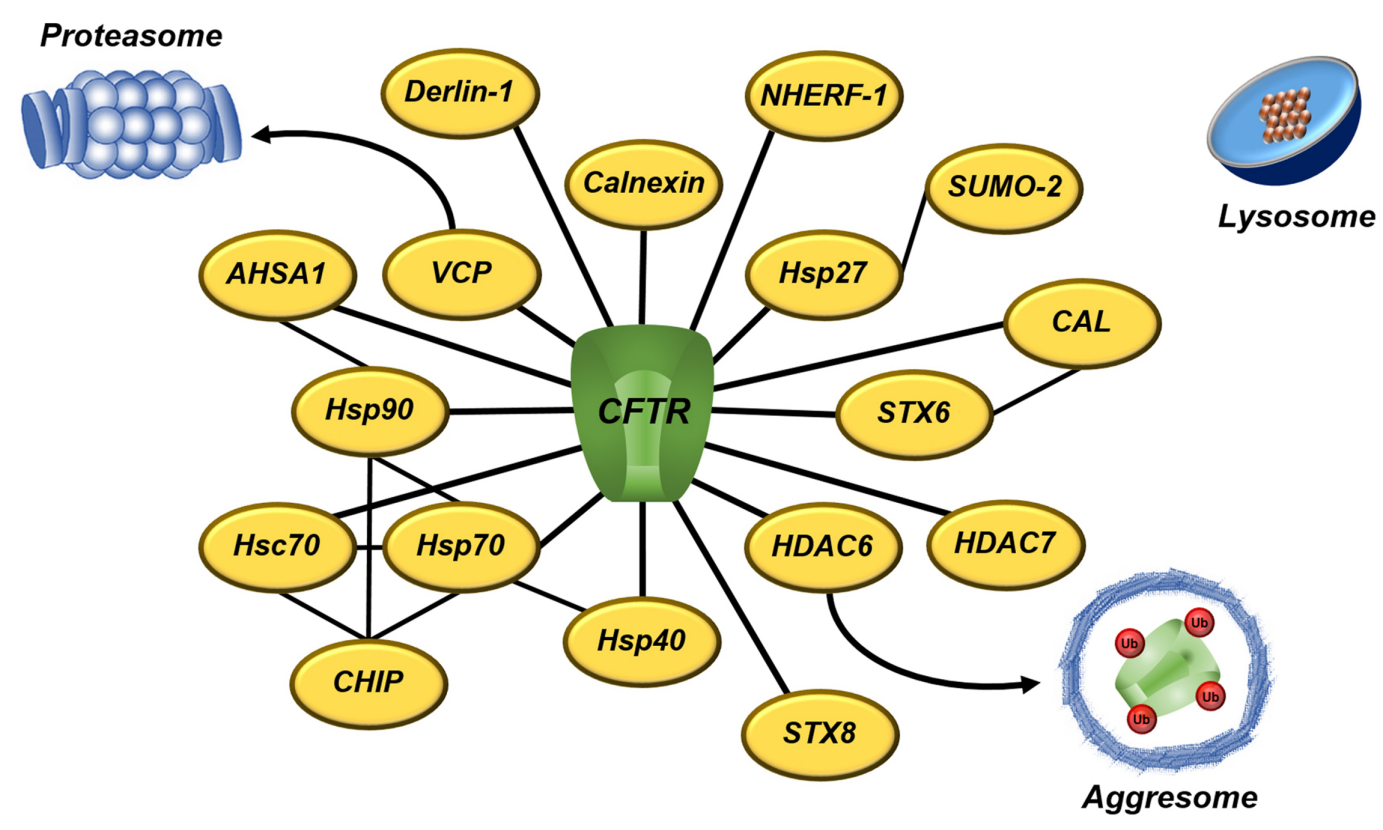

FIGURE 6 | A subset of proteostasis network engaged to CFTR degradation - CFTR interactome involves several quality control proteins that directly or indirectly target CFTR to degradation. Proteasomes and aggresomes eliminate CFTR that fails in acquire the native conformation. Lysosomes degrade CFTR removed from the cell surface during the recycling. The black lines denoted the interaction between CFTR and proteostasis components. AHSA1, activator of 90 kDA Hsp ATPase homolog 1; CAL, CFTR-associated ligand; CHIP, carboxyl terminus of Hsc70-interacting protein; CFTR, cystic fibrosis transmembrane conductance regulator; HDAC, histone deacetylase; Hsc, heat-shock cognate; Hsp, heat-shock protein; $\mathrm{NHERF} \mathrm{Na}^{+} / \mathrm{H}^{+}$exchanger regulatory factor; SUMO, small ubiquitin-like modifier; STX, syntaxin; Ub, ubiquitin; and VCP, vasolin-containing protein.

solely on the defect of a particular gene (Vu et al., 2015). CFTR gene is located at the chr7q31.2 and a genome-wide association analysis identified five loci that display significant relevance in the variable manifestation and progression of lung disease in CF (chr3q29, chr5p15.3, chr6p21.3, chr11p12-p13 and chrXq22-q23) (Corvol et al., 2015; Dang et al., 2016).

\section{CLASSES OF CFTR MUTATIONS AND CFTR MODULATORS}

The $\Delta$ F508 is the most prevalent CFTR mutation with about $60 \%$ of CF patients' chromosomes worldwide presenting this mutant (Bobadilla et al., 2002; Sosnay et al., 2013) (Figure 3). The remaining $40 \%$ present other CFTR mutations and there have been nearby 2,000 mutations reported in the Cystic Fibrosis Mutation Database (CFTR1 database) $)^{1}$. CFTR mutants can reduce protein expression, function, stability or a combination of these, and to help in understanding the nature of such gene and protein variability, CFTR defects have been classified into six classes (Amaral and Farinha, 2013; Quon and Rowe, 2016; Veit et al., 2016a) (Figure 7).

Distribution of CFTR mutants into classes may contribute to the application of precision medicine, since similar strategies might rescue CFTR from similar defects. However, the classification has a few caveats: (1) Numerous mutations have

\footnotetext{
${ }^{1}$ http://www.genet.sickkids.on.ca/Home.html
}

not been characterized, with respect to which group they should be allocated. The mutations' characteristics for a subset of known mutations can be found at the Clinical and Functional Translation of CFTR (CFTR2 database) ${ }^{2}$. (2) At first glance, CFTR mutations in the same group show similar characteristics, but they may respond differently to the same treatment. (3) Several mutations (e.g., $\Delta \mathrm{F} 508$ ) present pleiotropic defects, which means they could fit in more than one class. The major characteristic of $\Delta \mathrm{F} 508$ is the incomplete folding of the protein caused by NBD1 instability (class II) (Cheng et al., 1990; Jensen et al., 1995; Lukacs and Verkman, 2012), but this mutation also affects channel gating (class III) (Dalemans et al., 1991; Serohijos et al., 2008; Mendoza et al., 2012) and cell surface residence time (class VI) (Sharma et al., 2004; Swiatecka-Urban et al., 2005; Okiyoneda et al., 2010). Based on this limitation, new classifications are under debate, including a scheme that would be composed of the traditional classes I, II, III/IV, V, VI and their 26 combinations, totaling 31 CFTR mutations classes (Veit et al., 2016a).

Monotherapies could be efficient in overcoming the molecular defect of some CFTR mutations; however, given the complexity of pleiotropic CFTR variants, combination of treatments may be required to rectify their defects and thus achieve therapeutic levels in the patients (Amaral and Farinha, 2013; Quon and Rowe, 2016; Veit et al., 2016a). Libraries of compounds have been screened by high-throughput screening (HTS) to identify more

\footnotetext{
${ }^{2} \mathrm{http} / / \mathrm{cftr} 2 . \mathrm{org} /$
} 


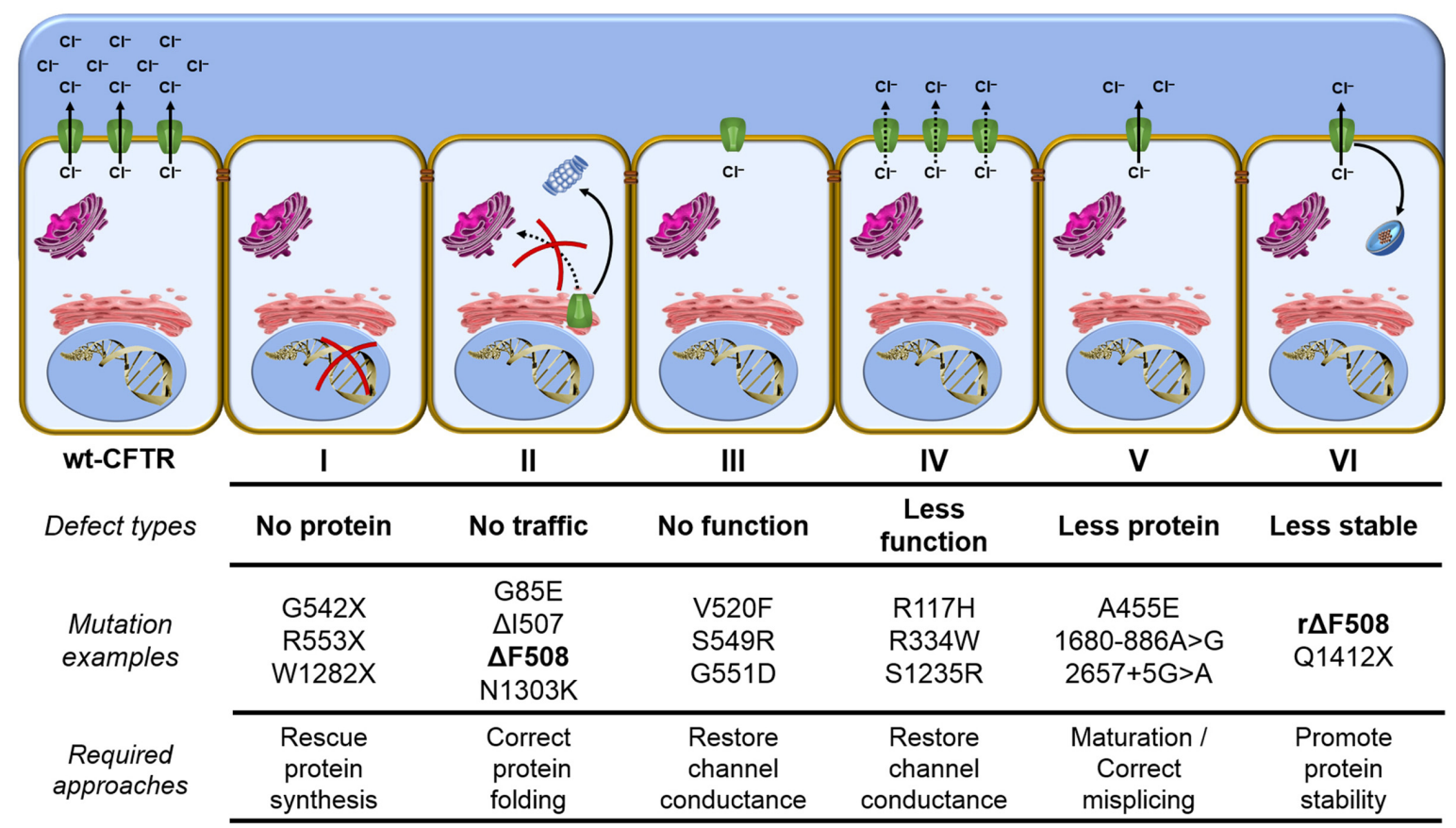

FIGURE 7 | Classes of CFTR mutations - Distribution of CFTR mutations into six functional classes according to the primary molecular defect: Class / mutants are no protein synthesis, since the presence of premature stop codons (class la) or frameshifts for deletions or insertions (class lb) preclude translation of full-length CFTR. Class I/ mutants are impaired trafficking protein, since CFTR fails to acquire complete folding and ER-associated degradation (ERAD) machinery eliminate the protein. Class III mutants are defective channel gating, since CFTR reach the cell surface, but it does not exhibit channel gating due to diminished ATP binding and hydrolysis. Class IV mutants are less functional proteins, since channel amount that achieve the plasma membrane could be similar to wt-CFTR, but it presents reduced chloride conductance. Class $V$ mutants are less protein maturation caused by amino acid substitution or alternative splicing, since the protein amount that reaches the cell surface is reduced and it also leads to loss of chloride transport due to reduction in the quantity of CFTR channels. Class VI mutants are less stable protein, since CFTR at the plasma membrane is removed during the recycling and it is sent for lysosome degradation. wt, wild type; CFTR, cystic fibrosis

transmembrane conductance regulator; $r \mathrm{~F} 508$, rescued $\Delta \mathrm{F} 508$ by low-temperature incubation; and ER, endoplasmic reticulum.

efficacious and non-cytotoxic drugs for application of precision medicine. Among these new pharmacological treatments, 'CFTR modulators' are small molecules that target specific defects caused by mutations in the CFTR gene and they are classified into five main groups: read-through agents, correctors, potentiators, stabilizers and amplifiers.

\section{Rescuing the Protein Synthesis}

Read-through agents could benefit CF patients bearing class I mutations, since the presence of a premature stop codon (class Ia) precludes protein synthesis of full-length CFTR (Quon and Rowe, 2016). Class Ia mutations represent about $9 \%$ of the mutants causing CF and they are present in more than $50 \%$ of Israeli CF patients (Kerem et al., 1997; Bobadilla et al., 2002). In this line, ribosomal 'over-reading' of a premature stop codon should permit the continuing translation to the normal end of the transcript. This readthrough effect was first observed with aminoglycoside antibiotics, such as gentamicin and tobramycin, which are commonly used for eradication of $P$. aeruginosa. Both antibiotics promoted expression of full-length CFTR at the PM and restored partially its chloride secretion in cell lines and transgenic mice (Howard et al., 1996; Du et al., 2002; Wilschanski et al., 2003). Despite these preclinical results, CF patients bearing nonsense mutations did not present CFTR activity after nasal application of aminoglycosides (Clancy et al., 2007). Furthermore, high systemic levels or long-term use of gentamycin has potential toxic effects in CF patients (Prayle et al., 2010).

Ataluren (formerly PTC124) is among the new drugs discovered by HTS. This drug suppressed the human G542X nonsense mutant in transgenic mice, restoring CFTR functional expression at the PM (Du et al., 2008). Thereafter, this drug resulted in some improvement in forced expiratory volume in $1 \mathrm{~s}\left(\mathrm{FEV}_{1}\right)$ of $\mathrm{CF}$ patients bearing nonsense mutations in phase II trials (Kerem et al., 2008; Sermet-Gaudelus et al., 2010; Wilschanski et al., 2011). However, these findings were inconclusive in the first long-term phase III trial, with only a subgroup of patients who were not receiving chronic inhaled aminoglycosides presenting a slight effect in $\mathrm{FEV}_{1}$ (Kerem et al., 2014). Ataluren has also shown limited premature stop codon suppression in CF rectal organoids (Zomer-van Ommen et al., 2016). Moreover, other read-through agents have shown promising results in preclinical experiments, including synthetic aminoglycosides (Rowe et al., 2011; Xue et al., 2014), ataluren derivatives (Pibiri et al., 2015, 2016), and the US Food and Drug Administration (FDA)-approved herbal agent, escin (Mutyam et al., 2016). 
For other class I mutations (class Ib), such as frameshifts caused by small deletions or insertions during protein synthesis, very little has been achieved in treatments yet.

\section{Rescuing the Protein Folding and Trafficking}

Correctors are small-molecules that enhance the conformational stability of CFTR, resulting in greater efficacy of protein folding and rescuing the trafficking of the mature CFTR to the PM (Pedemonte et al., 2005; Okiyoneda et al., 2013; Lopes-Pacheco et al., 2015; Quon and Rowe, 2016). CF patients bearing class II mutations, including $\Delta \mathrm{F} 508$, could benefit from correctors treatment, since these CFTR mutants fail to reach complete folding and the ER machinery targets the protein to be degraded (Van Goor et al., 2006; Atawade et al., 2015; Rapino et al., 2015; Lopes-Pacheco et al., 2016).

New treatments may target the defective CFTR structure directly by binding to the mutated protein (pharmacological chaperone) and/or indirectly by modulating CFTR interactome (proteostasis regulator). Some reports have shown that correctors act either as pharmacological chaperones (Wang et al., 2007a; Sampson et al., 2011; Eckford et al., 2014; Sinha et al., 2015) or as proteostasis regulators (Hegde et al., 2015; Lopes-Pacheco et al., 2015, 2016; Rapino et al., 2015). Based on the possible mechanism of action as pharmacological chaperones, correctors have been classified into three groups: 1) correctors that stabilize the interactions between NBD1 and intracellular loops 1 and 4 (e.g., C3, C18 and VX-809); 2) correctors that restore NBD2 stability and its interfaces with other CFTR domains (e.g., C4); and 3 ) correctors that directly stabilize NBD1 (Okiyoneda et al., 2013).

Lumacaftor (formerly VX-809) restored $\triangle$ F508-CFTR expression and function in human bronchial epithelial (HBE) cells (Van Goor et al., 2011). The higher efficacy of lumacaftor, compared to other correctors (C3 and C4), seems to be due to its effect on the early CFTR synthesis (Farinha et al., 2015). Despite progress in vitro, lumacaftor treatment by itself showed a significant decrease only in sweat chloride levels and no improvements in $\mathrm{FEV}_{1}$ in a phase II trial with $\Delta$ F508-homozygous patients (Clancy et al., 2012). Lumacaftor presented the most variable effects in primary HBE cells and rectal organoids bearing $\Delta \mathrm{F} 508$ in only one allele or other CFTR mutants in both alleles, with some mutants being 'unrescuable' (e.g., N1303K) (Atawade et al., 2015; Dekkers et al., 2016a,b). Furthermore, a synonymous mutation changing ATC to ATT at position 507 (I507) alters mRNA and protein structure (Lazrak et al., 2013), consequently, affecting the efficacy of correctors to rescue $\triangle$ F508-CFTR (Bali et al., 2016a,b). Aiming at greater effects, combinations of correctors have been evaluated and have been shown to enhance the rescue of CFTR bearing $\Delta F 508$, as well as other class II mutants, compared to monotherapies (Okiyoneda et al., 2013; Phuan et al., 2014; Hegde et al., 2015; Lopes-Pacheco et al., 2015, 2016; Rapino et al., 2015). Some correctors could also increase CFTR maturation of class $\mathrm{V}$ mutants caused by amino acid substitution, such as A455E (Dekkers et al., 2016a,b; Lopes-Pacheco et al., 2016). In addition, VIP rescued functional expression of $\triangle$ F508-CFTR by stimulating both PKA- and PKC-dependent pathways in nasal and bronchial epithelial cells (Rafferty et al., 2009; Alcolado et al., 2011). Many newly discovered correctors are being investigated, including VX-661 that presented more a favorable pharmacokinetic profile than lumacaftor (Cholon et al., 2014; Veit et al., 2014; Phuan et al., 2015) and is in phase III trials to $\triangle$ F508-homozygous and -heterozygous patients (NCT02347657, NCT02392234 and NCT02412111).

Besides the correctors, drugs that modulate proteostasis have been evaluated to restore CFTR functional expression at the PM, since wt-CFTR and $\triangle$ F508 present a rather different interactome during their processing and trafficking (Pankow et al., 2015). Cysteamine, a proteostasis regulator approved by the FDA for nephropathic cystinosis, has shown promise for treating CF. Cysteamine (reduced form of cystamine), in association with epigallocatechin gallate, restored beclin 1-dependent autophagy protein levels and depleted sequestrosome 1/p62, thereby correcting autophagy flux, and rescuing CFTR trafficking, function and stability at the PM. These findings were observed in lungs from $\mathrm{Cftr}^{\triangle F 508}$ mice, CFBE41o- cell line expressing $\triangle$ F508-CFTR, and primary nasal epithelial cells freshly harvested from $\Delta$ F508-homozygous patients (Luciani et al., 2012; Villella et al., 2013; De Stefano et al., 2014). Recently, a combination of cysteamine and epigallocatechin gallate decreased sweat chloride levels, as well as inflammatory biomarkers levels in the sputum, and tended to improve $\mathrm{FEV}_{1}$ in $\Delta \mathrm{F} 508$-homozygous and heterozygous (with a class II mutant in the second allele) patients in a phase II trial (Tosco et al., 2016). Several other proteostasis regulators have been investigated to rescue CFTR, including sildenafil analogs (Robert et al., 2008), oubain (Zhang et al., 2012), roscovitine (Norez et al., 2014), suberoylanilide hydroxamic acid (Hutt et al., 2010; Pankow et al., 2015) and latonduine analogs (Carlile et al., 2016). Silencing of RPL12, a ribosomal stalk protein, also rescued $\triangle F 508-C F T R$ and presented a synergistic effect with lumacaftor, restoring the mutant function to about $50 \%$ of the wt-CFTR in primary HBE cells bearing $\triangle \mathrm{F} 508$ in both alleles (Veit et al., 2016b).

\section{Restoring the Channel Conductance}

Potentiators are drugs that increase channel open probability, improving CFTR channel activity. Potentiators could benefit CF patients bearing class III and IV mutations, since CFTR is present at the PM, but it exhibits no gating or reduced activity (Van Goor et al., 2006, 2009, 2014; Eckford et al., 2012). Furthermore, patients bearing class I or II mutations for which protein synthesis or trafficking were rescued, but not proper channel activity, may benefit from this additional approach.

Ivacaftor (formerly VX-770) rescued CFTR channel gating in HBE cells bearing G551D mutation (Van Goor et al., 2009) through a nonconventional ATP-independent mechanism (Eckford et al., 2012). Ivacaftor also potentiated channel activity of CFTR bearing other class III or IV mutants in Fisher rat thyroid cells (Yu et al., 2012; Van Goor et al., 2014) and rescued forskolin-induced swelling in rectal organoids bearing CFTR mutants with residual function (Dekkers et al., 2016a). A subsequent series of phase II and III clinical trials showed that 
ivacaftor reduced sweat chloride levels and improved $\mathrm{FEV}_{1}$ in CF patients bearing G551D (Accurso et al., 2010; Ramsey et al., 2011; Davies et al., 2013a,b; McKone et al., 2014) or one of other eight class III mutants (G178R, S549N, S549R, G551S, G1244E, S1251N, S1255P, and G1349D) (De Boeck et al., 2014) in at least one allele. For $\mathrm{R} 117 \mathrm{H}$, a residual function mutant, ivacaftor decreased sweat chloride levels of all patients, but only individuals older than 18 years and with a polythymidine tract variant of $5 \mathrm{~T}$ presented improvements in $\mathrm{FEV}_{1}$ (Carter et al., 2015; Moss et al., 2015; Ronan et al., 2015). Currently, ivacaftor is available for CF patients bearing the aforementioned mutations.

Monotherapy with ivacaftor (Flume et al., 2012) or lumacaftor (Clancy et al., 2012) was unsuccessful in improving $\mathrm{FEV}_{1}$ of $\Delta$ F508-homozygous patients in phase II trials. A closer investigation of the pleiotropic defects caused by $\Delta F 508$ in CFTR reveals that combinations of drugs with different mechanism of actions will be required to obtain more efficient rescue of the mutated protein that may ultimately result in therapeutic levels in the patients (Okiyoneda et al., 2013; Phuan et al., 2014; Lopes-Pacheco et al., 2015; Veit et al., 2016a). Toward this goal, phase II and III trials tested the effects of coadministration of lumacaftor/ivacaftor. This approach reduced pulmonary exacerbations, slightly decreased sweat chloride levels and induced significant, but modest, improvements in $\mathrm{FEV}_{1}$ of $\Delta$ F508-homozygous patients (Boyle et al., 2014; Wainwright et al., 2015; Elborn et al., 2016). Recently, co-administration of lumacaftor/ivacaftor was licensed for $\Delta \mathrm{F} 508$-homozygous patients.

Some flavonoids also increase channel open probability of CFTR mutants (Galietta et al., 2001; Pyle et al., 2010; Yu et al., 2011). In particular, genistein and curcumin have shown synergy with lumacaftor to enhance forskolin-induced swelling in rectal organoids bearing CFTR mutants $\triangle$ F508, G551D and S1251N (Dekkers et al., 2016c). Ivacaftor has shown clinical benefits when administered by itself, but its effects could be even greater when used with other compounds for CFTR bearing G551D or R117H (Gentzsch et al., 2016; Lin et al., 2016; Yu et al., 2016). In addition, new potentiators are under investigation to restore channel activity of CFTR mutants, including QBW251 (NCT02190604) and GLPG1837 (NCT02690519 and NCT02707562), as well as dual activity compounds that act as both correctors and potentiators, such as aminoarylthiazoles (Pedemonte et al., 2011; Pesce et al., 2015) and rattlesnake phospholipase $A_{2}$ (Faure et al., 2016).

\section{Stabilizing the Protein at the Cell Surface}

Stabilizers are agents that anchor CFTR channel at the PM and decrease protein degradation rate, thereby correcting the instability of class VI mutants. Low-temperature incubation of cells bearing $\Delta$ F508 rescue CFTR to the PM (r $\Delta$ F508) (Sharma et al., 2001); however, the protein still presents reduced half-life due to both increased endocytosis (Swiatecka-Urban et al., 2005) and decreased recycling (Sharma et al., 2004). Lumacaftor also did not confer long-term stability of wt-CFTR for the mutant $\Delta$ F508 (He et al., 2013).

New treatments must rectify the intrinsic protein instability to rescue the steady state levels and augment CFTR residence time at the PM. In this line, hepatocyte growth factor (HGF) activated Rac1 signaling and promoted $\Delta \mathrm{F} 508$ stabilization favoring interaction of CFTR and NHERF-1 (Moniz et al., 2013). Lumacaftor also promoted interaction of CFTR and NHERF-1 (Arora et al., 2014), but co-administration of HGF/lumacaftor further increased the rescue of $\triangle F 508$-CFTR and enhanced protein anchoring at the PM, compared to lumacaftor alone (Loureiro et al., 2015). Administration of VIP (Rafferty et al., 2009; Alshafie et al., 2014) or activation of EPAC1, an exchange protein directly activated by cAMP (Lobo et al., 2016), also stabilized CFTR at the PM by promoting its interaction with NHERF-1 and by decreasing its endocytosis rate.

In addition, inhibition of $S$-nitrosoglutathione reductase enhanced $\Delta$ F508 maturation and stability by preventing interaction of CFTR with Hsp70/Hsp90 organizing protein (Marozkina et al., 2010; Zaman et al., 2016). Cavosonstat (formerly N91115) increased S-nitrosoglutathione levels in preclinical studies and it is the first CFTR stabilizer in phase II trials being evaluated for $\Delta$ F508-homozygous patients using the combination lumacaftor/ivacaftor (NCT02589236) or for those patients bearing gating mutants and receiving ivacaftor (NCT02724527).

\section{Correcting the Splicing}

Antisense oligonucleotides-based therapy is an emerging approach to correct class $\mathrm{V}$ mutations caused by alternative splicing that generate aberrant mRNA variants. About 11\% of mutations-causing CF occur by incorrect splicing and this approach has shown to modulate the splicing and restore normal full-length CFTR transcript, as well as rescue functional CFTR protein (Bonini et al., 2015; Igreja et al., 2016).

A synthetic RNA oligonucleotide, QR-010, is being evaluated in two phase I trials to assess: (1) the effects of inhaled single and multiple doses in $\Delta$ F508-homozygous patients (NCT02532764), and (2) the effects of intranasal administration in $\Delta F 508$ homozygous and -heterozygous patients (NCT02564354).

\section{PRECISION MEDICINE: BREAKTHROUGHS AND CHALLENGES TO TREATING ALL CF PATIENTS}

From the first pathological description of the disease until the discovery of the CFTR gene and its correlation with CF, therapeutic interventions were only aimed at reducing clinical symptoms and end-organ complications. Nowadays, based on the accumulated knowledge about CFTR protein (synthesis, folding, trafficking and degradation), many studies have sought more specific treatments to restore expression, function and stability of CFTR mutants, thereby overcoming the primary molecular defect that causes CF. As such, CFTR modulators provided new perspectives and advances in the treatment of patients bearing common and rare CFTR mutations.

Many clinical trials have completed the tests of safety and efficacy of CFTR modulators (Table 3). The first breakthrough in personalizing CF treatments came with the approval of ivacaftor (Kalydeco ${ }^{\mathrm{TM}}$ from Vertex Pharmaceuticals) for patients bearing 
TABLE 3 | Completed clinical trials of CFTR modulators in CF patients.

\begin{tabular}{|c|c|c|c|c|c|c|}
\hline $\begin{array}{l}\text { ClinicalTrials.gov ID } \\
\text { (formerly name) }\end{array}$ & Phase & Subjects & $\begin{array}{l}\text { Age } \\
\text { (years) }\end{array}$ & Drug(s) & Follow up & Reference(s) \\
\hline NCT00237380 & 2 & Nonsense mutations $s^{\mathrm{a}, \mathrm{b}}$ & $\geq 18$ & Ataluren & 56 days & Kerem et al., 2008 \\
\hline NCT00457821 & 2 & $\begin{array}{l}\text { G551D-homozygous } \\
\text { and -heterozygous }\end{array}$ & $\geq 18$ & Ivacaftor & 28 days & Accurso et al., 2010, 2014 \\
\hline NCT00458341 & 2 & $\begin{array}{l}\text { Nonsense } \\
\text { mutations } s^{a, c, d}\end{array}$ & $6-18$ & Ataluren & 28 days & Sermet-Gaudelus et al., 2010 \\
\hline NCT00865904 & 2 & $\Delta$ F508-homozygous & $\geq 18$ & Lumacaftor & 28 days & Clancy et al., 2012 \\
\hline $\begin{array}{l}\text { NCT00909532 } \\
\text { (STRIVE) }\end{array}$ & 3 & $\begin{array}{l}\text { G551D-homozygous } \\
\text { and -heterozygous }\end{array}$ & $\geq 12$ & Ivacaftor & 48 weeks & $\begin{array}{l}\text { Ramsey et al., 2011; Quittner } \\
\text { et al., } 2015\end{array}$ \\
\hline $\begin{array}{l}\text { NCT00953706 } \\
\text { (DISCOVER) }\end{array}$ & 2 & $\Delta$ F508-homozygous & $\geq 12$ & Ivacaftor & 16 weeks & Flume et al., 2012 \\
\hline $\begin{array}{l}\text { NCT01262352 } \\
\text { (ENVISION) }\end{array}$ & 2 & $\begin{array}{l}\text { G551D-homozygous } \\
\text { and -heterozygous }\end{array}$ & $\geq 6$ & Ivacaftor & 48 weeks & Davies et al., 2013a,b \\
\hline NCT01521338 (GOAL) & 4 & $\begin{array}{l}\text { G551D-homozygous } \\
\text { and -heterozygous }\end{array}$ & $\geq 6$ & Ivacaftor & 6 months & $\begin{array}{l}\text { Rowe et al., 2014; O'Connor } \\
\text { and Seegmiller, } 2016\end{array}$ \\
\hline NCT01531673 & 2 & $\begin{array}{l}\Delta \mathrm{F} 508 \text {-homozygous } \\
\text { and -heterozygous }\end{array}$ & $\geq 12$ & $\begin{array}{l}\text { VX-661 } \\
\text { and/or } \\
\text { Ivacaftor }\end{array}$ & 28 days & $* * *$ \\
\hline $\begin{array}{l}\text { NCT01614457 } \\
\text { (KONDUCT) }\end{array}$ & 3 & $\begin{array}{l}\mathrm{R} 117 \mathrm{H} \text {-homozygous } \\
\text { and -heterozygous }\end{array}$ & $\geq 6$ & Ivacaftor & 24 weeks & Moss et al., 2015 \\
\hline $\begin{array}{l}\text { NCT01614470 } \\
\text { (KONNECTION) }\end{array}$ & 3 & $\begin{array}{l}\text { Non-G551D gating } \\
\text { mutations in at least } \\
\text { one allele }\end{array}$ & $\geq 6$ & Ivacaftor & 24 weeks & De Boeck et al., 2014 \\
\hline NCT01707290 & 3 & $\begin{array}{l}\text { Non-G551D gating or } \\
\text { residual } \\
\text { function mutations in at } \\
\text { least one allele }{ }^{b, e, f}\end{array}$ & $\geq 6$ & Ivacaftor & 24 weeks & $* * *$ \\
\hline $\begin{array}{l}\text { NCT01807923 } \\
\text { (TRAFFIC) }\end{array}$ & 3 & $\Delta$ F508-homozygous & $\geq 12$ & $\begin{array}{l}\text { Lumacaftor } \\
\text { and } \\
\text { Ivacaftor }\end{array}$ & 24 weeks & $\begin{array}{l}\text { Wainwright et al., 2015; Elborn } \\
\text { et al., } 2016\end{array}$ \\
\hline $\begin{array}{l}\text { NCT01807949 } \\
\text { (TRANSPORT) }\end{array}$ & 3 & $\Delta$ F508-homozygous & $\geq 12$ & $\begin{array}{l}\text { Lumacaftor } \\
\text { and } \\
\text { Ivacaftor }\end{array}$ & 24 weeks & $\begin{array}{l}\text { Wainwright et al., 2015; Elborn } \\
\text { et al., } 2016\end{array}$ \\
\hline NCT01897233 & 3 & $\Delta$ F508-homozygous & $6-11$ & $\begin{array}{l}\text { Lumacaftor } \\
\text { and } \\
\text { Ivacaftor }\end{array}$ & 24 weeks & $* * *$ \\
\hline NCT01931839 & 3 & $\Delta$ F508-homozygous & $\geq 12$ & $\begin{array}{l}\text { Lumacaftor } \\
\text { and } \\
\text { Ivacaftor }\end{array}$ & 96 weeks & $* * *$ \\
\hline
\end{tabular}

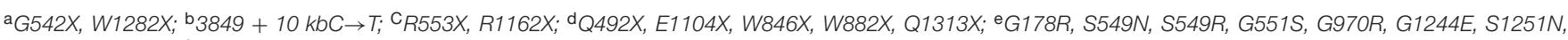
S1255P, G1349D; ${ }^{\mathrm{f}} \mathrm{R} 117 \mathrm{H}$, E56K, P67L, D110E, D110H, R117C, R347H, R352Q, A455E, D579G, S945L, L206W, R1070W, F1074L, D1152H, S1235R, D1270N, $2789+5 G \rightarrow A, 3272-26 A \rightarrow G, 711+5 G \rightarrow A, 3120 G \rightarrow A, 1811+1.6 \mathrm{kbA-}>\mathrm{G}, 711+3 A \rightarrow G, 1898+3 A \rightarrow G, 1898+1 G \rightarrow A, 1717-I G \rightarrow A, 1717-8 G \rightarrow A, 1342-$ $2 A \rightarrow C, 405+3 A \rightarrow C, 1716 G / A 1811+I G \rightarrow C, 1898+5 G \rightarrow T, 3850-3 T \rightarrow G, I N S 14 b+5 G \rightarrow A, 1898+I G \rightarrow T, 4005+2 T \rightarrow C, 621+3 A \rightarrow G, 621+I G \rightarrow T$. ***Manuscript not available yet. 
G551D-CFTR in at least one allele, initially licensed by the FDA and later by the European Medicines Agency (EMA). Clinical studies showed that ivacaftor treatment improves $\mathrm{FEV}_{1}$ and almost normalizes sweat chloride levels (Accurso et al., 2010; Ramsey et al., 2011; Davies et al., 2013a,b), as well as reduces frequency of infections caused by $P$. aeruginosa (Rowe et al., 2014), enhances nutritional status (Borowitz et al., 2016), insulin secretion (Bellin et al., 2013) and quality of life (Quittner et al., 2015). Acute administration of ivacaftor also corrects smooth muscle abnormalities, improving airway distensibility and vascular tone (Adam et al., 2016). Clinical benefits obtained by ivacaftor treatment have proven durable effects, with no new safety concerns (Sawicki et al., 2015). Ivacaftor was later licensed for patients bearing one of the other eight gating mutations (De Boeck et al., 2014) and a mutant with residual function in at least one allele (Moss et al., 2015), increasing to $5-7 \%$ the number of individuals worldwide who may benefit from this pharmaceutical treatment. Despite these optimistic results, patients using ivacaftor should continue with conventional therapies, which have also been optimized, to prevent pulmonary exacerbations and complications (Smyth et al., 2014).

Ataluren (Translarna ${ }^{\mathrm{TM}}$ from PTC Therapeutics) was approved by the EMA for individuals who have Duchenne muscular dystrophy caused by nonsense mutation. After the inconclusive results from the first phase III trial, a second one is ongoing to evaluate the effects of ataluren in CF patients bearing nonsense mutations and not receiving inhaled aminoglycosides (NCT02139306).

Recently, the FDA and the EMA licensed the combination lumacaftor/ivacaftor (Orkambi ${ }^{\mathrm{TM}}$ from Vertex Pharmaceuticals) for $\Delta$ F508-homozygous patients, adding a new pharmaceutical treatment to $40-45 \%$ of CF patients worldwide. Results from a phase II trial evaluating this combination in $\Delta \mathrm{F} 508$-homozygous patients (Boyle et al., 2014) encouraged the pursuance of two long-term phase III trials (24 weeks) involving more than 1,100 people. Co-administration of lumacaftor/ivacaftor proved clinical effectiveness, despite fairly small improvement in $\mathrm{FEV}_{1}$ (Wainwright et al., 2015; Elborn et al., 2016). A longer-term (96 weeks) phase III trial showed that co-administration of lumacaftor/ivacaftor presents sustained benefit with decreased pulmonary exacerbations, reduced rate of lung function decline and improved nutritional status of $\Delta \mathrm{F} 508$-homozygous patients (Konstan et al., 2016). Although it is still a glimmer of light at the end of the tunnel, this combination provides proof of concept that pleiotropic CFTR mutants can be rescued at therapeutic levels, representing a new hope to restore a healthy life to patients.

Intriguingly, studies using cell lines bearing $\triangle$ F508-CFTR showed that: (1) Chronic ivacaftor exposure $(>1 \mu \mathrm{M})$ reduced CFTR correction obtained by lumacaftor treatment (Cholon et al., 2014; Veit et al., 2014); however, exposure to a lower concentration $(<1 \mu \mathrm{M})$ of ivacaftor did not inhibit the functional correction obtained by lumacaftor (Matthes et al., 2016). Therefore, co-administration of lumacaftor/ivacaftor may present a dose-dependent inhibitory effect. Addition of $\mathrm{C} 4$ also reversed the negative effects of ivacaftor on lumacaftor-corrected
CFTR (Bali et al., 2016b). (2) P. aeruginosa infection reduces CFTR chloride secretion stimulated by lumacaftor and/or ivacaftor treatments (Stanton et al., 2015). (3) In cells previously treated with lumacaftor, the PPQC system still recognizes the CFTR delivered at the PM as improperly folded and removes the protein from the cell surface (Loureiro et al., 2015). Taken together, the experimental results indeed may explain the modest findings in the clinical trials and highlight the importance of better evaluating drug-drug and drug-protein interactions for future drug combinations.

The introduction of Kalydeco ${ }^{\mathrm{TM}}$ and Orkambi ${ }^{\mathrm{TM}}$ to the market add feasible treatment for about $50 \%$ of all CF patients worldwide (Table 4). Unfortunately, there is still an unmet need for the other half of the CF population, who are $\Delta$ F508heterozygous and bear a wide range of other variants (so-called orphan mutants). The patient registries and the clinical studies network have optimized the clinical phase of drug development due to heterogeneous distribution of CFTR variants (De Boeck et al., 2011; Rowe et al., 2012). Randomized controlled trials are suitable for common mutations, but many CFTR mutants are rare or even unique, requiring different approaches. As such, modified single-patient ('N-of-1') is an alternative trial design in which single patients serve as their own control by measuring outcome parameters after multiple cycles of on-off treatment (Zucker et al., 2010; Duan et al., 2013).

Rectal organoids have also shown to be a good model for identifying drug-responsive individuals with rare CFTR genotypes (Dekkers et al., 2016a; Vijftigschild et al., 2016). In addition, both Kalydeco ${ }^{\mathrm{TM}}$ and Orkambi ${ }^{\mathrm{TM}}$ are in ongoing clinical trials to: (1) evaluate the longer-term safety and efficacy of the treatments; (2) increase the panel of mutations that may benefit from these drugs; and (3) evaluate the safety and efficacy in younger patients. Since the progressive damage caused by CF

\begin{tabular}{|c|c|c|c|}
\hline $\begin{array}{l}\text { Pharmaceutical } \\
\text { treatment }\end{array}$ & CFTR mutations & $\begin{array}{l}\text { Jurisdiction } \\
\text { approved }\end{array}$ & $\begin{array}{l}\text { Age group } \\
\text { licensed }\end{array}$ \\
\hline \multirow[t]{6}{*}{ Kalydeco $^{\mathrm{TM}}$} & G551D* & $\begin{array}{c}\text { United States, } \\
\text { Europe and } \\
\text { Canada }\end{array}$ & $>2$ years \\
\hline & & $\begin{array}{l}\text { Australia and } \\
\text { New Zealand }\end{array}$ & $>6$ years \\
\hline & $\begin{array}{l}\text { G178R, S549N, } \\
\text { S549R, G551S, } \\
\text { G1244E, S1251N, } \\
\text { S1255P, G1349D* }\end{array}$ & $\begin{array}{c}\text { United States, } \\
\text { Europe and } \\
\text { Canada }\end{array}$ & $>2$ years \\
\hline & & Australia & $>6$ years \\
\hline & $\mathrm{R} 117 \mathrm{H}^{*}$ & United States & $>2$ years \\
\hline & & $\begin{array}{l}\text { Europe and } \\
\text { Canada }\end{array}$ & $>18$ years \\
\hline Orkambi ${ }^{\mathrm{TM}}$ & $\begin{array}{l}\Delta \text { F508- } \\
\text { homozygous }\end{array}$ & $\begin{array}{c}\text { United States, } \\
\text { Europe and } \\
\text { Canada }\end{array}$ & $>12$ years \\
\hline
\end{tabular}

*Mutation in at least one allele. 
starts during babyhood, earlier treatments are critical to offering the best chances of improving long-term outcomes.

In an attempt to achieve greater clinical outcomes, two new classes of CFTR modulators are under investigation in association with Orkambi ${ }^{\mathrm{TM}}$ : (1) PTI-428 is an amplifier that doubled the activity of the combination lumacaftor/ivacaftor in HBE cells bearing $\triangle$ F508-CFTR in both alleles (Proteostasis Therapeutics, 2016); and (2) cavosonstat is a stabilizer that improved $\triangle$ F508-CFTR stability at the PM after co-administration of lumacaftor/ivacaftor (Nivalis Therapeutics, 2016). Moreover, other correctors and potentiators are advancing in triple combination for treatment of $\Delta$ F508-homozygous and -heterozygous patients: GLPG1837/GLPG2222/GLPG2665 (Galapagos, 2015), VX152/VX-661/ivacaftor and VX-440/VX-661/ivacaftor (Vertex Pharmaceuticals, 2015).

An important limitation that has to be addressed regarding these new pharmaceutical treatments is the high cost (over US\$250,000 per patient per year), which renders difficult their acquisition for CF patients living in low-income countries. Investments in the identification of drugs already available and able to overcome the primary molecular defect of CF could be another way, cheaper and fast, to optimize treatments.

Soon after the CFTR gene was discovered and cloned (Kerem et al., 1989; Riordan et al., 1989), gene therapy was proposed to cure lung disease in CF. The idea of introducing a copy of wt-CFTR in airway cells to re-establish the production of functional protein seemed graceful and 'simple'. Although CF is a 'simple' monogenic disorder, most approaches (viral and non-viral) failed to cross the trapped mucus, thereby resulting in inefficient transduction of CFTR gene, and some of them promoting immune response activation (Di Gioia et al., 2015; Quon and Rowe, 2016). Nevertheless, researchers have sought more efficient gene delivery systems. Poly ( $\beta$-amino esters)based biodegradable polymers were able to deliver a plasmid that encodes full-length CFTR in murine lungs and CFBE41o- cell lines expressing wt-CFTR or $\Delta$ F508 (Suk et al., 2014), as well as to penetrate in freshly expectorated mucus from CF patients (Mastorakos et al., 2015). Furthermore, repeated nebulization of pGM169/GL67A, a gene-liposome complex, showed feasible, safe and reproducible results in murine lungs (Alton et al., 2014), as well as stabilized lung function of CF patients, thereby presenting a significant, albeit modest, benefit in $\mathrm{FEV}_{1}$ in a phase II trial (NCT01621867) (Alton et al., 2015). These systems may also be an interesting approach to delivery of CFTR modulators, bringing some benefits in usefully exploited patients' treatment: (1) noninvasive administration route by inhalation/nebulization; (2) delivering directly to a specific lung region or defined cell type; (3) reduced systemic side effects and no serum proteins sequestered; and (4) sustained release, which decrease times and dose of therapies to maintain the beneficial effects (Vij et al., 2010; Suk et al., 2014; Alton et al., 2015; Kim et al., 2015).

\section{CFTR MODULATORS RESCUING MUTANTS IN OTHER ABC TRANSPORTERS}

Plasma membrane proteins belong to some of the largest families, encoding ion channels, transporters, aquaporins and ATP-powered pumps. Forty-nine proteins constitute the ABC transporters family in the human genome (Loo and Clarke, 2008; Vasiliou et al., 2009) and among these proteins, CFTR is unique in possessing a RD and in functioning as a chloride channel (Winter and Welsh, 1997; Gadsby et al., 2006; Serohijos et al., 2008). Mutations in ABC transporters have been linked to diseases and, since these transporters share a similar domain organization and structure, some CFTR modulators have been evaluated to rescue protein trafficking and function of other $\mathrm{ABC}$ transporters. Here are some examples: ABCA4 (Sabirzhanova et al., 2015), ABCB1 (or P-glycoprotein) (Wang et al., 2007b), ABCC6 (or multidrug resistance-associated protein 6) (Zhou et al., 2013), ABCC8 (or SUR1) (Sampson et al., 2013), and ABCG2 (Woodward et al., 2013). These findings show that CFTR modulators could be a promising treatment for several diseases caused by mutations in other ABC transporters.

\section{CONCLUSION}

Since the discovery that CFTR loss-of-activity causes CF, the biological understanding of CFTR processing has advanced steadily and opened new perspectives for more sophisticated treatments, which act directly on the molecular defect that causes the disease. The presence of CFTR modulators in the market has affected positively the clinical outcomes of CF patients, representing a new dawn in their lives. Although there is still a long way to go in completely restoring a healthy life for all CF patients, research from the bench to the clinic is moving forward at an accelerated pace toward precision medicines, which would enable "the highest attainable standard of health," as enshrined in the constitution of the World Health Organization.

\section{AUTHOR CONTRIBUTIONS}

The author confirms being the sole contributor of this work and approved it for publication.

\section{ACKNOWLEDGMENTS}

The author thanks Solon Leite (Pharm.D.), Elga Bandeira (M.Sc, Ph.D) and Fernanda Cruz (M.D., Ph.D.) for the suggestions and comments during the manuscript writing and revision, Rachel Veloso (from Trends Language) and Fernanda Graciolli (from The Editoria) for editing the manuscript, and Nilo Lopes (CF patient) for being a motivation in the writing of this state-of-art. 


\section{REFERENCES}

Accurso, F. J., Rowe, S. M., Clancy, J. P., Boyle, M. P., Dunitz, J. M., Durie, P. R., et al. (2010). Effect of VX-770 in persons with cystic fibrosis and the G551DCFTR mutation. N. Engl. J. Med. 363, 1991-2003. doi: 10.1056/NEJMoa0909825

Accurso, F. J., Van Goor, F., Zha, J., Stone, A. J., Dong, Q., Ordonez, C. L., et al. (2014). Sweat chloride as a biomarker of CFTR activity: proof of concept and ivacaftor clinical trial data. J. Cyst. Fibros. 13, 139-147. doi: 10.1016/j.jcf.2013.09.007

Adam, R. J., Hisert, K. B., Dodd, J. D., Grogan, B., Launspach, J. L., Barnes, J. K., et al. (2016). Acute administration of ivacaftor to people with cystic fibrosis and a G551D-CFTR mutation reveals smooth muscle abnormalities. JCI Insight 1, e86183. doi: 10.1172/jci.insight.86183

Adler, F. R., Aurora, P., Barker, D. H., Barr, M. L., Blackwell, L. S., Bosma, O. H., et al. (2009). Lung transplantation for cystic fibrosis. Proc. Am. Thorac. Soc. 6 , 619-633. doi: 10.1513/pats.2009008-088TL

Ahner, A., Gong, X., Schmidt, B. Z., Peters, K. W., Rabeh, W. M., Thibodeau, P. H., et al. (2013). Small heat shock proteins target mutant cystic fibrosis transmembrane conductance regulator for degradation via a small ubiquitin-like modifier-dependent pathway. Mol. Biol. Cell 24, 74-84. doi: 10.1091/mbc.E12-09-0678

Ahner, A., Nakatsukasa, K., Zhang, H., Frizzell, R. A., and Brodsky, J. L. (2007). Small heat-shoch proteins select deltaF508-CFTR for endoplasmic reticulumassociated degradation. Mol. Biol. Cell 18, 806-814. doi: 10.1091/mbc.E06-050458

Alcolado, N., Conrad, D. J., Rafferty, S., Chappe, F. G., and Chappe, V. M. (2011). VIP-dependent increase in F508del-CFTR membrane localization is mediated by PKCE. Am. J. Physiol. Cell Physiol. 301, C53-C65. doi: 10.1152/ajpcell. 00568

Alshafie, W., Chappe, F. G., Li, M., Anini, Y., and Chappe, V. M. (2014) VIP regulates CFTR membrane expression and function in Calu-3 cells by increasing its interaction with NHERF1 and P-ERM in a VPAC1- and PKCE-dependent manner. Am. J. Physiol. Cell Physiol. 307, C107-C119. doi: 10.1152/ajpcell.00296.2013

Alton, E. W., Armstrong, D. K., Asbhy, D., Bayfield, K. J., Bilton, D., Bloomfield, E. V., et al. (2015). Repeated nebulisation of non-viral CFTR gene therapy in patients with cystic fibrosis: a randomised, double-blind, placebocontrolled, phase 2b trial. Lancet Respir. Med. 3, 684-691. doi: 10.1016/S22132600(15)00245-3

Alton, E. W., Boyd, A. C., Cheng, S. H., Davies, J. C., Davies, L. A., Dayan, A., et al. (2014). Toxicology study assessing efficacy and safety of repeated administration of lipid/DNA complexes to mouse lung. Genet. Ther. 21, 89-95. doi: 10.1038/gt.2013.61

Amaral, M. D., and Farinha, C. M. (2013). Rescuing mutant CFTR: a multi-task approach to a better outcome in treating cystic fibrosis. Curr. Pharm. Des. 19, 3497-3508. doi: 10.2174/13816128113199990318

Armstead, J., Morris, J., and Denning, D. W. (2014). Multi-country estimate of different manifestations of aspergillosis in cystic fibrosis. PLoS ONE 9:e98502. doi: 10.1371/journal.pone.0098502

Arora, K., Moon, C., Zhang, W., Yarlagadda, S., Penmatsa, H., Ren, A., et al. (2014). Stabilizing rescued surface-localized $\Delta$ F508 CFTR by potentiation of its interaction with $\mathrm{Na}(+) / \mathrm{H}(+)$ exchanger regulatory factor 1 . Biochemistry 53 , 4369-4379. doi: 10.1021/bi401263h

Atawade, N. T., Uliyakina, I., Farinha, C. M., Clarke, L. A., Mendes, K., Solé, A., et al. (2015). Measurements of functional responses in human primary lung cells as a basis for personalized therapy for cystic fibrosis. EBioMedicine 2, 147-153. doi: 10.1016/j.ebiom.2014.12.005

Balch, W. E., Roth, D. M., and Hutt, D. M. (2011). Emergent properties of proteostasis in managing cystic fibrosis. Cold Spring Harb. Perspect. Biol. 3, a004499. doi: 10.1101/cshperspect.a004499

Bali, V., Lazrak, A., Guroji, P., Fu, L., Matalon, S., and Bebok, Z. (2016a). A synonymous códon change alters the drug sensitivity of $\triangle F 508$ cystic fibrosis transmembrane conductance regulator. FASEB J. 30, 201-213. doi: 10.1096/fj.15-273714

Bali, V., Lazrak, A., Guroji, P., Matalon, S., and Bebok, Z. (2016b). Mechanistic approaches to improve correction of the most common disease-causing mutation in cystic fibrosis. PLoS ONE 77:e0155882. doi: 10.1371/journal.pone.0155882
Bellin, M. D., Laguna, T., Leschyshyn, J., Regelmann, W., Dunitz, J., Billings, J., et al. (2013). Insulinsecretion improves in cystic fibrosis following ivacaftor correction of CFTR: a small pilot study. Pediat. Diabetes 14, 417-421. doi: 10.1111/pedi.12026

Bhatt, J. M. (2013). Treatment of pulmonary exacerbations in cystic fibrosis. Eur. Respir. Rev. 22, 205-216. doi: 10.1183/09059180.00006512

Bilan, F., Thoreau, V., Nacfer, M., Dérand, R., Norez, C., Cantereau, A., et al. (2004). Syntaxin 8 impairs trafficking of cystic fibrosis transmembrane conductance regulator (CFTR) and inhibits its channel activity. J. Cell Sci. 117, 1923.1935. doi: $10.1242 /$ jcs. 01070

Bilton, D., Robinson, P., Cooper, P., Gallagher, C. G., Kolbe, J., Fox, H., et al. (2011). Inhaled dry powder mannitol in cystic fibrosis: an efficacy and safety study. Eur. Respir. J. 38, 1071-1080. doi: 10.1183/09031936.00187510

Bobadilla, J. L., Macek, M. Jr., Fine, J. P., and Farrell, P. M. (2002). Cystic fibrosis: a worldwide analysis of CFTR mutations - correlation with incidence dataand application to screening. Hum. Mutat. 19, 575-606. doi: 10.1002/humu.10041

Bonestroo, H. J., de Winter-de Groot, K. M., van der Ent, C. K., and Arets, H. G. (2010). Upper and lower airway cultures in children with cystic fibrosis: do not negect the upper airways. J. Cyst. Fibros. 9, 130-134. doi: 10.1016/j.jcf.2010.01.001

Bonini, J., Varilh, J., Raynal, C., Thèze, C., Beyne, E., Audrezet, M. P., et al. (2015). Small-scale high-throughput sequencing-based identification of new therapeutic tools in cystic fibrosis. Genet. Med. 17, 796-806. doi: 10.1038/gim.2014.194

Borowitz, D., Lubarsky, B., Wilschanski, M., Munck, A., Gelfond, D., Bodewes, F., et al. (2016). Nutritional status improves in cystic fibrosis patients with the G551D mutation after treatment with ivacaftor. Dig. Dis. Sci. 61, 198-207. doi: 10.1007/s10620-015-3834-2

Boyault, C., Gilquin, B., Zhang, Y., Rybin, V., Garman, E., Meyer-Klaucke, W., et al (2006). HDAC6-p97/VCP controlled polyubiquitin chain turnover. EMBO J. 25 3357-3366. doi: 10.1038/sj.emboj.7601210

Boyle, M. P., Bell, S. C., Konstan, M. W., MocColley, S. A., Rowe, S. M. Rietschel, E., et al. (2014). A CFTR corrector (lumacaftor) and a CFTR potentiator (ivacaftor) for treatment of patients with cystic fibrosis who have a phe508del CFTR mutation: a phase 2 randomised controlled trial. Lancet Respir. Med. 2, 527-538. doi: 10.1016/S2213-2600(14)70132-8

Brazilian Cystic Fibrosis Study Group [GBEFC] (2016). Registro Brasileiro de Fibrose Cística 2014. Available at: http://conteudosportal.com.br/GBEFC/ wp-content/uploads/2016/03/Registro2014_v09.pdf [accessed July 27, 2016]

Burgel, P. R., Bellis, G., Olesen, H. V., Viviani, L., Zolin, A., Blasi, F., et al. (2015). Future trends in cystic fibrosis demography in 34 European countries. Eur. Respir. J. 46, 133-141. doi: 10.1183/09031936.00196314

Calabrese, F., Lunardi, F., Nannini, N., Balestro, E., Loy, M., Marulli, G., et al. (2015). Higher risk of acute cellular rejection in lung transplant recipients with cystic fibrosis. Ann. Transplant. 20, 769-776. doi: 10.12659/AOT. 894785

Carlile, G. W., Robert, R., Matthes, E., Yang, Q., Solari, R., Hatley, R., et al. (2016). Latonduine analogues restore F508del-CFTR trafficking through modulation of PARP-3 and PARP-16 activity. Mol. Pharmacol. 90, 65-79. doi: $10.1124 / \mathrm{mol} .115 .102418$

Carter, S., Kelly, S., Caples, E., Grogan, B., Doyle, J., Gallagher, C. G., et al. (2015). Ivacaftor as salvage therapy in a patients with cystic fibrosis genotype F508del/R117H/IVS8-5T. J. Cyst. Fibros. 14, e4-e5. doi: 10.1016/j.jcb.2015.01.010

Castellani, C., Massie, J., Sontag, M., and Southern, K. W. (2016). Newborn screening for cystic fibrosis. Lancet Respir. Med. 4, 653-661. doi: 10.1016/S22132600(16)00053-9

Chappe, V., Hinkson, D. A., Zhu, T., Chang, X. B., Riordan, J. R., and Hanrahan, J. W. (2003). Phosphorylation of protein kinase C sites in NBD1 and the R domains control CFTR channel activation by PKA. J. Physiol. 548, 39-52. doi: 10.113/jphysiol.2002.035790

Chen, J. H., Stoltz, D. A., Karp, P. H., Ernst, S. E., Pezzulo, A. A., Moninger, T. O., et al. (2010). Loss of anion transport without increased sodium absorption characterizes newborn porcine cystic fibrosis airway epithelia. Cell 143, $911-$ 923. doi: 10.1016/j.cell.2010.11.029

Cheng, J., Cebotaru, V., Cebotaru, L., and Guggino, W. B. (2010). Syntaxin 6 and CAL mediate the degradation of the cystic fibrosis transmembrane conductance regulator. Mol. Biol. Cell 21, 1178-1187. doi: 10.1091/mbc.E09-03-0229 
Cheng, J., and Guggino, W. (2013). Ubiquitination and degradation of CFTR by the E3 ubiquitin ligase MARCH2 through its association with adaptor proteins CAL and STX6. PLOS ONE 8:e68001. doi: 10.1371/journal.pone.00 68001

Cheng, J., Moyer, B. D., Milewski, M., Loffing, J., Ikeda, M., Mickle, J. E., et al. (2002). A Golgi-associated PDZ domain protein modulates cystic fibrosis transmembrane regulator plasma membrane expression. J. Biol. Chem. 277, 3520-3529. doi: 10.1074/jbc.M110177200

Cheng, S. H., Gregory, R. J., Marshall, J., Paul, S., Souza, D. W., White, G. A., et al. (1990). Defective intracellular transport and processing of CFTR is the molecular basis of most cystic fibrosis. Cell 63, 827-834. doi: 10.1016/00928674(90)90148-8

Cholon, D. M., Quinney, N. L., Fulcher, M. L., Esther, C. R. Jr., Das, J., Dokholyan, N. V., et al. (2014). Potentiator ivacaftor abrogates pharmacological correction of $\triangle$ F508 CFTR in cystic fibrosis. Sci. Transl. Med. 6, 246ra96. doi: 10.1126/scitranslmed.3008680

Clancy, J. P., Rowe, S. M., Accurso, F. J., Aitken, M. L., Amin, R. S., Ashlock, M. A., et al. (2012). Results of a phase IIa study of VX-809, an investigational CFTR corrector compound, in subjects with cystic fibrosis homozygous for the F508del-CFTR mutation. Thorax 67, 12-18. doi: 10.1136/thoraxjnl-2011200393

Clancy, J. P., Rowe, S. M., Bebok, Z., Aitken, M. L., Gibson, R., Zeitlin, P. L., et al. (2007). No detectable improvements in cystic fibrosis transmembrane conductance regulator by nasal aminoglycosides in patients with cystic fibrosis with stop mutations. Am. J. Respir. Cell. Mol. Biol. 37, 57-66. doi: 10.1165/rcmb.2006-0173OC

Cohen-Cymberknoh, M., Shoseyov, D., Breuer, O., Shamali, M., Wilschanski, M., and Kerem, E. (2016). Treatment of cystic fibrosis in low-income countries. Lancet Respir. Med. 4, 91-92. doi: 10.1016/S2213-2600(15)00507-X

Cohen-Cymberknoh, M., Shoseyov, D., and Kerem, E. (2011). Managing cystic fibrosis: strategies that increase life expectancy and improve quality of life. Am. J. Respir. Crit. Care Med. 183, 1463-1471. doi: 10.1164/rccm.201009-1478CI

Collaco, J. M., Blackman, S. M., Raraigh, K. S., Corvol, H., Rommens, J. M., Pace, R. G., et al. (2016). Sources of variation in sweat chloride measurements in cystic fibrosis. Am. J. Repir. Crit. Care Med. doi: 10.1164/rccm.201603-0459OC [Epub ahead of print].

Coppinger, J. A., Hutt, D. M., Razvi, A., Koulov, A. V., Pankow, S., Yates, J. R. III, et al. (2012). A chaperone trap contributes to the onset of cystic fibrosis. PLoS ONE 7:e37682. doi: 10.1371/journal.pone.0037682

Corvol, H., Blackman, S. M., Boëlle, P. Y., Gallins, P. J., Pace, R. G., Stonebraker, J. R., et al. (2015). Genome wide association meta-analysis identifies five modifier loci of lung disease severity in cystic fibrosis. Nat. Commun. 6, 8382. doi: $10.1038 /$ ncomms9382

Cowley, E. S., Kopf, S. H., LaRiviere, A., Ziebis, W., and Newman, D. K. (2015). Pediatric cystic fibrosis sputum can be chemically dynamic, anoxic and extremely reduced due to hydrogen sulfide formation. MBio 6:e00767-15. doi: $10.1128 / \mathrm{mBio} .00767-15$

Cystic Fibrosis Canada [CFC] (2016). The Canadian Cystic Fibrosis Registry: 2014 Annual Report. Available at: https://cysticfibrosis.uberflip.com/i/705240-cysticfibrosis-canada-registry [accessed July 27, 2016].

Cystic Fibrosis Federation Australia [CFFA] (2016). Cystic Fibrosis in Australia 2014: 17th Annual Report Australian Cystic Fibrosis Data Registry. https://www. cysticfibrosis.org.au/media/wysiwyg/CF-Australia/medical-documents/CFA_ DataRegistryReport_2014_Final.pdf [accessed Aug 05, 2016].

Cystic Fibrosis Foundation [CFF] (2015). Patient Registry: Annual Data Report 2014. Available at: https://www.cff.org/2014_CFF_Annual_Data_Report_to_ the_Center_Directors.pdf/ [accessed May 08, 2016]

Dalemans, W., Barbry, P., Campigny, G., Jallat, S., Dott, K., Dreyer, D., et al. (1991). Altered chloride ion channel kinetics associated with the delta F508 cystic fibrosis mutation. Nature 354, 526-528. doi: 10.1038/354526a0

Dang, H., Gallins, P. J., Pace, R. G., Guo, X. L., Stonebraker, J. R., Corvol, H., et al. (2016). Novel variation at chr11p13 associated with cystic fibrosis lung disease severity. Hum. Genome Var. 3, 16020. doi: 10.1038/hgv.2016.20

Davies, J. C., Cunningham, S., Harris, W. T., Lapey, A., Regelmann, W. E., Sawicki, G. S., et al. (2016). Safety, pharmacokinetics, and pharmacodynamics of ivacaftor in patients aged 2-5 years with cystic fibrosis and a CFTR gating mutation (KIWI): an open-label, single-arm study. Lancet Respir. Med. 4, 107-115. doi: 10.1016/S2213-2600(15)00545-7
Davies, J. C., Sheridan, H., Bell, N., Cunningham, S., Davis, S. D., Elborn, J. S., et al. (2013a). Assessment of clinical response to ivacaftor with lung clearance index in cystic fibrosis patients with a G551D-CFTR mutation and preserved spirometry: a randomised controlled trial. Lancet Respir. Med. 1, 630-638. doi: 10.1016/S2213-2600(13)70182-6

Davies, J. C., Wainwright, C. E., Canny, G. J., Chilvers, M. A., Howestine, M. S., Munck, A., et al. (2013b). Efficacy and safety of ivacaftor in patients aged 6 to 11 years with cystic fibrosis with a G551D mutation. Am. J. Respir. Crit. Care Med. 187, 1219-1225. doi: 10.1164/rccm.201301-0153OC

De Boeck, K., Bulteel, V., Tiddens, H., Wagner, T., Fajac, I., Conway, S., et al. (2011). Guideline on the design and conduct of cystic fibrosis clinical trials: the European Cystic Fibrosis Society-Clinical Trials Network (ECFS-CTN). J. Cyst. Fibros. 10, S67-S74. doi: 10.1016/S1569-1993(11)60010-6

De Boeck, K., Munck, A., Walker, S., Saro, A., Hiatt, P., Gilmartin, G., et al. (2014). Efficacy and safety of ivacaftor with cystic fibrosis and a nonG551D gating mutation. J. Cyst. Fibros. 13, 674-680. doi: 10.1016/j.jcf.2014. 09.005

De Stefano, D., Villella, V. R., Esposito, S., Tosco, A., Sepe, A., De Gregorio, F. et al. (2014). Restoration of CFTR function in patients with cystic fibrosis carrying the F508del-CFTR mutation. Autophagy 10, 2053-2074. doi: $10.4161 / 15548624.2014 .973737$

Dekkers, J. F., Bekers, G., Kruisselbrink, E., Vonk, A., de Jonge, H. R., Janssens, H. M., et al. (2016a). Characterizing responses to CFTR-modulating drugs using rectal organoids derived from subjects with cystic fibrosis. Sci. Transl. Med. 8, 344ra84. doi: 10.1124/scitranslmed.aad8278

Dekkers, J. F., Gogorza Gondra, R. A., Kruisselbrink, E., Vonk, A. M., Janssens, H. M., de Winter-de Groot, K. M., et al. (2016b). Optimal correction of distinct CFTR folding mutants in rectal cystic fibrosis organoids. Eur. Respir. J. 48, 451-458. doi: 10.1183/13993003.01192-2015

Dekkers, J. F., Van Mourik, P., Vonk, A. M., Kruisselbrink, E., Berkers, G., de Winter-de Groot, K. M., et al. (2016c). Potentiator synergy in rectal organoids carrying S1251N, G551D, or F508del CFTR mutation. J. Cystc. Fibros. doi: 10.1016/j.jcf.2016.04.007 [Epub ahead of print]

Di Gioia, S., Trapani, A., Castellani, S., Carnoe, A., Belgiovine, G., Craparo, E. F., et al. (2015). Nanocomplexes for gene therapy of respiratory diseases: targeting and overcoming the mucus barrier. Pulm. Pharmacol. Ther. 34, 8-24. doi: 10.1016/j.pupt.2015.07.003

Djik, F. N., and Fitzgerald, D. A. (2012). The impact of newborn screening and earlier intervention on the clinical course of cystic fibrosis. Paediatr. Respir. Rev. 13, 220-225. doi: 10.1016/j.prrv.2012.05.003

Du, M., Jones, J. R., Lanier, J., Keeling, K. M., Lindsey, J. R., Tousson, A., et al. (2002). Amoniglycoside suppression of a premature stop mutation in a Cftr-/mouse carrying a human CFTR-G542X transgene. J. Mol. Med. 80, 595-604. doi: 10.1007/s00109-002-0363-1

Du, M., Liu, X., Welch, E. M., Hirawat, S., Peltz, S. W., and Bedwell, D. M. (2008). PTC124 is an orally bioavailable compound that promotes suppression of the human CFTR-G542X nonsense allele in a CF mouse model. Proc. Natl. Acad. Sci. U.S.A. 105, 2064-2069. doi: 10.1073/pnas.071195105

Duan, N., Kravitz, R. L., and Schmid, C. H. (2013). Single-patient (nof-1) trials: pragmatic clinical decision methodology for patient-centered comparative effectiveness research. J. Clin. Epidemiol. 66, S21-S28. doi: 10.1016/j.jclinepi.2013.04.006

Eckford, P. D., Li, C., Ramjeesingh, M., and Bear, C. E. (2012). Cystic fibrosis transmembrane conductance regulator (CFTR) potentiator VX-770 (ivacaftor) opens the defective channel gate of mutant CFTR in a phosphorylationdependent but ATP-independent manner. J. Biol. Chem. 287, 36639-36649. doi: 10.1074/jbc.M112.393637

Eckford, P. D., Ramjeesingh, M., Molinski, S., Pasyk, S., Dekkers, J. F., Li, C., et al. (2014). VX-809 and related corrector compounds exhibit secondary activity stabilizing active F508del-CFTR after its partial rescue to the cell surface. Chem. Biol. 21, 666-678. doi: 10.1016/j.chembiol.2014.02.021

Elborn, J. S., Ramsey, B. W., Boyle, M. P., Konstan, M. W., Huang, X., Marigowda, G., et al. (2016). Efficacy and safety of lumacaftor/ivacaftor combination therapy in patients with cystic fibrosis homozygous for phe508del CFTR by pulmonary function subgroup: a pooled analysis. Lancet Respir. Med. 4, 617-626. doi: 10.1016/S2213-2600(16)30121-7

Elkins, M. R., Robinson, M., Rose, B. R., Harbour, C., Moriarty, C. P., Marks, G. B., et al. (2006). A controlled trial of long-term inhaled hypertonic saline in 
patients with cystic fibrosis. N. Engl. J. Med. 354, 229-240. doi: 10.1056/NEJMoa 043900

European Cystic Fibrosis Society [ECFS] (2016). ECFS Patient Registry: Annual Data Report 2013. Available at: https://www.ecfs.eu/sites/default/files/images/ ECFSPR_Report2013_02.2016.pdf [accessed May 08, 2016].

Farinha, C. M., and Amaral, M. D. (2005). Most F508del-CFTR is targeted to degradation at na early folding checkpoint and independently of calnexin. Mol. Cell. Biol. 25, 5242-5252. doi: 10.1128/MCB.25.12.5242-5252.2005

Farinha, C. M., Nogueira, P., Mendes, F., Penque, D., and Amaral, M. D. (2002). The human DnaJ homologue (Hdj)-1/heat shock protein (Hsp) 40 co-chaperone is required for the in vivo statilization of cystic fibrosis transmembrane conductance regulator by Hsp70. Biochem. J. 336, 797-806. doi: 10.1042/bj20011717

Farinha, C. M., Sousa, M., Canato, S., Scdmidt, A., Uliyakina, I., and Amaral, M. D. (2015). Increased efficacy of VX-809 in different cellular systems results from na early stabilization effect of F508del-CFTR. Pharmacol. Res. Perspect. 3, e00152. doi: $10.1002 /$ prp2.152

Farrell, P. M., Rosenstein, B. J., White, T. B., Accurso, F. J., Castellani, C., Cutting, G. R., et al. (2008). Guidelines for diagnosis of cystic fibrosis in newborns through older adults: cystic fibrosis doundation consensus report. J. Pediatr. 153, S4-S14. doi: 10.1016/j.jpeds.2008.05.005

Faure, G., Bakouh, N., Lourdel, S., Odolczyk, N., Premchandar, A., Servel, N., et al. (2016). Rattlesnake phospholipase A2 increases CFTR-chloride channel current and corrects $\triangle$ F508CFTR dysfunction: impact in cystic fibrosis. J. Mol. Med. 428, 2898-2915. doi: 10.1016/j.jmb.2016.05.016

Favia, M., Guerra, L., Faneli, T., Cardone, R. A., Monterisi, S., Di Sole, F., et al. (2010). $\mathrm{Na}+/ \mathrm{H}+$ exchanger regulatory fator 1 onverexpression-dependent increase of cytoskeleton organization is fundamental in the rescue of F508del cystic fibrosis transmembrane conductance regulator in human airway CFBE41o- cells. Mol. Biol. Cell 21, 73-86. doi: 10.1091/mbc.E09-03-0185

Feranchak, A. P., Sontag, M. K., Wagener, J. S., Hammond, K. B., Accurso, F. J., and Sokol, R. J. (1999). Prospective, long-term study of fat-soluble status in children with cystic fibrosis identified by newborn screen. J. Pediatr. 135, 601-610. doi: 10.1016/S0022-3476(99)70059-4

Flume, P. A., Liou, T. G., Borowitz, D. S., Li, H., Yen, K., Ordoñez, C. L., et al. (2012). Ivacaftor in subjects with cystic fibrosis who are homozygous for the F508del-CFTR mutation. Chest 142, 718-724. doi: 10.1378/chest.11.2672

Fuchs, H. J., Borowitz, D. S., Christiansen, D. H., Morris, E. M., Nash, M. L., Ramsey, B. W., et al. (1994). Effect of aerolized recombinant human DNase on exacerbations of respiratory symptoms and on pulmonary function in patients with cystic fibrosis. The pulmozyme study group. N. Engl. J. Med. 331, 637-642. doi: 10.1056/NEJM199409083311003

Gadsby, D. C., Vergani, P., and Csanády, L. (2006). The ABC protein turned chloride channel whose failure causes cystic fibrosis. Nature 23, 477-483. doi: 10.1038 /nature 04712

Galapagos, N. V. (2015). Galapagos Advances Triple Combination Therapy in Cystic Fibrosis. Available at: http://www.glpg.com/docs/view/8829a660-en [accessed May 18, 2016].

Galietta, L. J., Springsteel, M. F., Eda, M., Niedzinski, E. J., By, K., Haddadin, M. J., et al. (2001). Novel CFTR chloride channel activators identified by screening of combinatorial libraries based on flavone and benzoquinolizinium lead compounds. J. Biol. Chem. 276, 19723-19728. doi: 10.1074/jbc.M101892200

Gentzsch, M., Dang, H., Dang, Y., Garcia-Caballero, A., Suchindran, H., Boucher, R. C., et al. (2010). The cystic fibrosis transmembrane conductance regulator impedes proteolytic stimulation of the epithelial Na+ channel. J. Biol. Chem. 285, 32227-32232. doi: 10.1074/jbc.M110.155259

Gentzsch, M., Ren, H. Y., Houck, S. A., Quinney, N. L., Cholon, D. M., Sopha, P., et al. (2016). Restoration of R117H CFTR folding and function in human airway cells through combination treatment with VX-809 and VX-770. Am. J. Physiol. Lung Cell. Mol. Physiol. doi: 10.1152/ajplung.00186.2016 [Epub ahead of print].

Glozman, R., Okiyoneda, T., Mulvihill, C. M., Rini, J. M., Barriere, H., and Lukacs, G. L. (2009). N-glycans are direct determinants of CFTR folding and stability in secretory and endocytic membrane traffic. J. Cell Biol. 184, 847-862. doi: $10.1083 /$ jcb. 200808124

Gong, X., Ahner, A., Roldan, A., Lukacs, G. L., Thibodeau, P. H., and Frizzell, R. A. (2016). Non-native conformers of cystic fibrosis transmembrane conductance regulator $\mathrm{NBDq}$ are recognized by Hsp27 and conjugated to SUMO-2 for degradation. J. Biol. Chem. 291, 2004-2017. doi: 10.1074/jbc.M115.685628
Guerra, L., Fanelli, T., Favia, M., Riccardi, S. M., Busco, G., Cardone, R. A., et al. (2005). $\mathrm{Na}+/ \mathrm{H}+$ exchanger regulatory factor isoform 1 overexpression modulates cystic fibrosis transmembrane conductance regulator (CFTR) expression and activity in human airway 16HBE14o- cells and rescues deltaF508 CFTR functional expression in cystic fibrosis cells. J. Biol. Chem. 280, 4092540933. doi: 10.1074/jbc.M505103200

Gustafsson, J. K., Ermund, A., Ambort, D., Johansson, M. E., Nilsson, H. E., Thorell, K., et al. (2012). Bicarbonate and functional CFTR channel are required for proper mucin secretion and link cystic fibrosis with its mucus phenotype. J. Exp. Med. 209, 1263-1272. doi: 10.1084/jem.20120562

He, L., Kota, P., Aleksandrov, A. A., Cui, L., Jensen, T., Dokholyan, N. V., et al. (2013). Correctors of $\triangle F 508$ CFTR restore global conformational maturation without thermally stabilizing the mutant protein. FASEB J. 27, 536-545. doi: 10.1096/fj.12-216119

Hegde, R. N., Parashuraman, S., Iorio, F., Ciciriello, F., Capuani, F., Carissimo, A., et al. (2015). Unravelling druggable signalling networks that control F508delCFTR proteostasis. Elife 4, e10365. doi: 10.7554/eLife. 10365

Howard, M., Frizzell, R. A., and Bedwell, D. M. (1996). Aminoglycoside antibiotics restore CFTR function by overcoming premature stop mutations. Nat. Med. 2, 467-469. doi: 10.1038/nm0496-467

Hutt, D. M., Herman, D., Rodrigues, A. P., Noel, S., Pilewski, J. M., Marreson, J., et al. (2010). Reduced histone deacetylase 7 activity restores function to misfolded CFTR in cystic fibrosis. Nat. Chem. Biol. 6, 25-33. doi: 10.1038/nchembio. 275

Igreja, S., Clarke, L. A., Botelho, H. M., Marques, L., and Amaral, M. D. (2016). Correction of a cystic fibrosis splicing mutation by antisense oligonucleotides. Hum. Mutat. 37, 209-215. doi: 10.1002/humu.22931

Itani, O. A., Chen, J. H., Karp, P. H., Ernst, S., Keshavjee, S., Parekh, K., et al. (2011). Human cystic fibrosis airway epithelia have reduced $\mathrm{Cl}^{-}$conductance but not increased $\mathrm{Na}^{+}$conductance. Proc. Natl. Acad. Sci. U.S.A. 108, 10260-10265. doi: 10.1073/pnas. 1106695108

Jensen, T. J., Loo, M. A., Pind, S., Williams, D. B., Goldberg, A. L., and Riordan, J. R. (1995). Multiple proteolytic systems, including the proteasome, contribute to CFTR processing. Cell 83, 129-135. doi: 10.1016/0092-8674(95) 90241-4

Jorth, P., Staudinger, B. J., Wu, X., Hisert, K. B., Hayden, H., Garudathri, J., et al. (2015). Regional isolation drives bacterial diversification within cystic fibrosis lungs. Cell Host Microbe 18, 307-319. doi: 10.1016/j.chom.2015.07.006

Kakoi, S., Yorimitsu, T., and Sato, K. (2013). COPII machinery cooperates with ERlocalized Hsp40 to sequester misfolded membrane protein into ER-associated compartments. Mol. Biol. Cell 24, 633-642. doi: 10.1091/mbc.E12-08-0639

Kalnins, D., and Wilschanski, M. (2012). Maintenance of nutritional status in patients with cystic fibrosis: new and emerging therapies. Drug Des. Devel. Ther. 6, 151-161. doi: 10.2147/DDDT.S9258

Kawaguchi, Y., Kovacs, J. J., McLaurin, A., Vance, J. M., Ito, A., and Yao, T. P. (2003). The acetylase HDAC6 regulates aggresome formation and cell viability in response to misfolded protein stress. Cell 115, 727-738. doi: 10.1016/S00928674(03)00939-5

Kerem, B., Chiba-Falek, O., and Kerem, E. (1997). Cystic fibrosis in Jews: frequency and mutation distribution. Genet. Test. 1, 35-39. doi: 10.1089/gte.1997.1.35

Kerem, B., Rommens, J. M., Buchanan, J. A., Markiewicz, D., Cox, T. K., Chakravarti, A., et al. (1989). Identification of the cystic fibrosis gene: genetic analysis. Science 245, 1073-1080. doi: 10.1126/science.2570460

Kerem, E., Hirawat, S., Armoni, S., Yaakov, Y., Shoseyov, D., Cohen, M., et al. (2008). Effectiveness of PTC124 treatment of cystic fibrosis caused by nonsense mutations: a prospective phase II trial. Lancet 372, 719-727. doi: 10.1016/S0140-6736(08)61168-X

Kerem, E., Konstan, M. W., De Boeck, K., Accurso, F. J., Sermet-Gaudelus, I., Wilschanski, M., et al. (2014). Ataluren for the treatment of nonsense-mutation cystic fibrosis: a randomised, double-blind, placebo-controlled phase 3 trial. Lancet Respir. Med. 2, 539-547. doi: 10.1016/S2213-2600(14)70100-6

Kim, J., O’Neill, J. D., Dorrello, N. V., Baccheatta, M., and Vunjak-Novakovic, G. (2015). Targeted delivery of liquid microvolumes into the lung. Proc. Natl. Acad. Sci. U.S.A. 112, 11530-11535. doi: 10.1073/pnas.1512613112

Kim, Y. E., Hipp, M. S., Bracher, A., Hayer-Hartl, M., and Hartl, F. U. (2013). Molecular chaperone functions in protein folding and proteostasis. Ann. Rev. Biochem. 82, 323-355. doi: 10.1146/annurev-biochem.060208092442 
Konstan, M. W., McKone, E., Moss, R. B., Marigowda, G., Cooke, J., Huang, X., et al. (2016). "Evidence for reduced rate of lung function decline and sustained benefit with combination lumacaftor and ivacaftor (LUM/IVA) therapy in patients (pts) $\geq 12$ years of age with cystic fibrosis (CF) homozygous for the F508del-CFTR mutation," in Poster at the 8th European Conference on Rare Diseases \& Orphan Products (ECRD): Poster 108, Edinburgh.

Koulov, A. V., LaPointe, P., Lu, B., Razvi, A., Coppinger, J., Dong, M. Q., et al. (2010). Biological and structural basis for Ahal regulation of Hsp90 ATP activity in maintaining proteostasis in human disease cystic fibrosis. Mol. Biol. Cell 21, 871-884. doi: 10.1091/mbc.E09-12-1017

Kunzelmann, K., Kathöfer, S., and Greger, R. (1995). $\mathrm{Na}^{+}$and $\mathrm{Cl}^{-}$conductances in airway epithelial cells: increased $\mathrm{Na}^{+}$conductance in cystic fibrosis. Pflugers. Arch. 431, 1-9. doi: 10.1007/BF00374371

Kwon, S. H., Pollard, H., and Guggino, W. B. (2007). Knockdown of NHERF1 enhances degradation of temperature rescued deltaF508 CFTR from the cell surface of human airway cells. Cell. Physiol. Biochem. 20, 763-772. doi: $10.1159 / 000110436$

LaFayette, S. L., Houle, D., Beaudoin, T., Wojewodka, G., Radzioch, D., Hoffman, L. R., et al. (2015). Cystic fibrosis-adapted Pseudomonas aerugiona quorum sensing lasR mutants cause hyperinflammatory responses. Sci. Adv. 1, e1500199. doi: 10.1126/sciadv.1500199

Lazrak, A., Fu, L., Bali, V., Bartoszewski, R., Rab, A., Havasi, V., et al. (2013). The silent codon change I507-ATC- > ATT contributes to the severity of the $\Delta$ F508 CFTR channel dysfuntion. FASEB J. 27, 4630-4645. doi: 10.1096/fj.13-227330

Lin, W. Y., Sohma, Y., and Hwang, T. C. (2016). Synergistic potentiation of CFTR gating by two chemically distinct potentiators, ivacaftor (VX-770) and NPPB. Mol. Pharmacol. 90, 275-285. doi: 10.1124/mol.116.104570

Lobo, M. J., Amaral, M. D., Zaccolo, M., and Farinha, C. M. (2016). EPAC1 activation by cAMP stabilizes CFTR at the membrane by promoting its interaction with NHERF1. J. Cell Sci. 129, 2599-2612. doi: 10.1242/jcs.185629

Loo, T. W., and Clarke, D. M. (2008). Mutational analysis of ABC proteins. Arch. Biochem. Biophys. 476, 51-64. doi: 10.1016/j.abb.2008.02.025

Lopes-Pacheco, M., Boinot, C., Sabirzhanova, I., Morales, M. M., Guggino, W. B., and Cebotaru, L. (2015). Combination of correctors rescue $\triangle F 508$-CFTR by reducing its association with Hsp40 and Hsp27. J. Biol. Chem. 290, 2563625645. doi: 10.1074/jbc.M115.671925

Lopes-Pacheco, M., Sabirzhanova, I., Rapino, D., Morales, M. M., Guggino, W. B., and Cebotaru, L. (2016). Correctors rescue CFTR mutation in nucleotidebunding domain 1 (n.d.) by modulating proteostasis. Chembiochem 17, 493505. doi: 10.102/cbic. 201500620

Loureiro, C. A., Matos, A. M., Dias-Alves, Â, Pereira, J. F., Uliykina, I., Barros, P., et al. (2015). A molecular switch in the scaffold NHERF1 enables misfolded CFTR to evade the peripheral quality control checkpoint. Sci. Signal 8, ra48. doi: 10.1126/scisignal.aaa1580

Luciani, A., Villella, V. R., Esposito, S., Brunetti-Pierri, N., Medina, D., Settembre, C., et al. (2010). Defective CFTR induces aggresome formation and lung inflammation in cystic fibrosis through ROS-mediated autophagy inhibition. Nat. Cell Biol. 12, 863-875. doi: 10.1038/ncb2090

Luciani, A., Villella, V. R., Esposito, S., Gavina, M., Russo, I., Silano, M., et al. (2012). Targeting autophagy as a novel strategy for faciliting the therapeutic action of potentiatios on $\Delta$ F508 cystic fibrosis transmembrane conductance regulator. Autophagy 8, 1657-1672. doi: 10.4161/auto.21483

Lukacs, G. L., and Verkman, A. S. (2012). CFTR: folding, misfolding and correcting the $\Delta$ F508 conformational defect. Trend Mol. Med. 18, 81-91. doi: 10.1016/j.molmed.2011.10.003

Lyczak, J. B., Cannon, C. L., and Pier, G. B. (2002). Lung infections associated with cystic fibrosis. Clin. Microbiol. Rev. 15, 194-222. doi: 10.1128/CMR.15.2.194222.2002

MacKenzie, T., Gifford, A. H., Sabadosa, K. A., Quinton, H. B., Knapp, E. A., Goss, C. H., et al. (2014). Longevity of patients with cystic fibrosis in 2000 to 2010 and beyond: survival analysis of the Cystic Fibrosis Foundation patient registry. Ann. Intern. Med. 161, 233-241. doi: 10.7326/M13-0636

Maisonneuve, P., Marshall, B. C., Knapp, E. A., and Lowenfels, A. B. (2013). Cancer risk in cystic fibrosis: a 20 -year nationwide study from the United States. J. Natl. Cancer. Inst. 105, 122-129. doi: 10.1093/jnci/djs481

Marozkina, N. V., Yemen, S., Borowitz, M., Liu, L., Plapp, M., Sun, F., et al. (2010). Hsp 70/Hsp 90 organizing protein as a nitrosylation target in cystic fibrosis therapy. Proc. Natl. Acad. Sci. U.S.A. 107, 11393-11398. doi: 10.1073/pnas.0909128107

Marson, F. A., Hortencio, T. D., Aguiar, K. C., and Ribeiro, J. D. (2015). Demographic, clinical and laboratory parameters of cystic fibrosis during the last two decades: acomparative analysis. BMC Pulm. Med. 15:3. doi: 10.1186/1471-2466-3

Mastorakos, P., da Silva, A. L., Chisholm, J., Song, E., Choi, W. K., Boyle, M. P., et al. (2015). Highly compacted biodegradable DNA nanoparticles capable of overcoming the mucus barrier for inhaled lung gene delivery. Proc. Natl. Acad. Sci. U.S.A. 112, 8720-8725. doi: 10.1073/pnas.1502281112

Matthes, E., Goepp, J., Carlile, G. W., Luo, Y., Dejgaard, K., Billet, A., et al. (2016). Low free drug concentration prevents inhibition of F508del CFTR functional expression by the potentiator VX-770 (ivacaftor). Br. J. Pharmacol. 173, 459-470. doi: 10.1111/bph.13365

McKone, E. F., Borowitz, D., Devinek, P., Griese, M., Konstan, M. W., Wainwright, C., et al. (2014). Long-term safety and efficacy of ivacaftor in patients with cystic fibrosis who have the Gly551Asp-CFTR mutation: a phase 3, open-label extension study (PERSIST). Lancet Respir. Med. 2, 902-910. doi: 10.1016/S2213-2600(14)70218-8

Meacham, G. C., Lu, Z., King, S., Sorscher, E., Tousson, A., and Cyr, D. M. (1999). The Hdj-2/Hsc70 chaperone pair facilitates early steps in CFTR biogenesis. EMBO J. 18, 1492-1505. doi: 10.1093/emboj/18.6.1492

Meacham, G. C., Patterson, C., Zhang, W., Younger, J. M., and Cyr, D. M. (2001). The Hsc70 co-chaperone CHIP targets immature CFTR for proteasomal degradation. Nat. Cell Biol. 3, 100-105. doi: 10.1038/35050509

Mendoza, J. L., Schmidt, A., Li, Q., Nuvaga, E., Barrett, T., Bridges, R. J., et al. (2012). Requirements for efficient correction of $\triangle F 508$ CFTR revealed by analyses of evolved sequences. Cell 148, 164-174. doi: 10.1016/j.cell.2011.11.023

Moniz, S., Souza, M., Moraes, B. J., Mendes, B. J., Palma, M., Barreto, C., et al. (2013). HGF stimutation of Rac signaling enhances pharmacological correction of the most prevalente cystic fibrosis mutant F508del-CFTR. ACS Chem. Biol. 8, 432-442. doi: 10.1021/cb300484r

Moskowitz, S. M., Chmiel, J. F., Sernen, D. L., Cheng, E., Gibson, R. L., Marshall, S. G., et al. (2008). Clinical practice and genetic counseling for cystic fibrosis and CFTR-related disorders. Genet. Med. 10, 851-868. doi: 10.1097/GIM.0b013e31818e55a2

Moss, R. B., Flume, P. A., Elborn, J. S., Cooke, J., Rowe, S. M., McColley, S. A., et al. (2015). Efficacy and safety of ivacaftor in patients with cystic fibrosis who have an Arg117His-CFTR mutation: a double-blind randomised controlled trial. Lancet Respir. Med. 3, 524-533. doi: 10.1016/S2213-2600(15)00201-5

Mutyam, V., Du, M., Xue, X., Keeling, K. M., White, E. L., Bostwick, J. R., et al. (2016). Discovery of clinically approved agents that promote suppression of CFTR nonsense mutations. Am. J. Respir. Crit. Care Med. doi: 10.1164/rccm.201601-0154OC [Epub ahead of print].

Nivalis Therapeutics (2016). Nivalis Therapeutics Expands N91115 Clinical Development Program in Cystic Fibrosis. Available at: http://ir.nivalis.com/pressreleases/detail/40/nivalis-therapeutics-expands-n91115-clinical-development [accessed May 18, 2016].

Norez, C., Vandebrouck, C., Bertrand, J., Noel, D., Durieu, E., Oumata, N., et al. (2014). Roscovitine is a proteostasis regulator that corrects the trafficking defect of F508del-CFTR by a CDK-independent mechanism. Br. J. Pharmacol. 171, 4831-4849. doi: 10.1111/bph.12859

O'Connor, M. G., and Seegmiller, A. (2016). The effects of ivacaftor on CF fatty acid metabolism: an analysis from GOAL study. J. Cyst. Fibros. doi: 10.1016/j.jcf.2016.07.006 [Epub ahead of print].

Okiyoneda, T., Barrière, H., Bagdány, M., Rabeh, W. M., Du, K., Höhfeld, J., et al. (2010). Peripheral protein quality controle removes unfolded CFTR from de plasma membrane. Science 329, 805-810. doi: 10.1126/science.11 91542

Okiyoneda, T., Niibori, A., Harada, K., Kohno, T., Michalak, M., Duszyk, M., et al. (2008). Role of calnexin in the ER quality control and productive folding of CFTR; differential effect of calnexin knockout on wild-type and deltaF508 CFTR. Biochim. Bhiophys. Acta 1783, 1585-1594. doi: 10.1016/j.bbamcr.2008.04.002

Okiyoneda, T., Veit, G., Dekkers, J. F., Bagdany, M., Soya, N., Xu, H., et al. (2013). Mechanism-based corrector combination restores $\triangle$ F508-CFTR folding and function. Nat. Chem. Biol. 9, 444-454. doi: 10.1038/nchembio.1253 
Pankow, S., Bamberger, C., Calzolari, D., Martínez-Bartolomé, S., MavalléeAdam, M., Balch, W. E., et al. (2015). $\triangle$ F508 CFTR interactome remodelling promotes rescue of cystic fibrosis. Nature 528, 510-516. doi: 10.1038/nature15729

Pedemonte, N., Lukacs, G. L., Du, K., Caci, E., Zegarra-Moran, O., Galietta, L. J., et al. (2005). Small-molecule correctors of defective deltaF508-CFTR cellular processing identified by high-throughput screening. J. Clin. Invest. 115, 2564-2571. doi: 10.1172/JCI24898

Pedemonte, N., Tomati, V., Sondo, E., Caci, E., Millo, E., Armirotti, A., et al. (2011). Dual activity of aminoarylthiazoles on the trafficking and gating defects of the cystic fibrosis transmembrane conductance regulator chloride channel caused by cystic fibrosis mutations. J. Biol. Chem. 286, 15215-15226. doi: 10.1074/jbc.M110.184267

Pesce, E., Belloti, M., Liessi, N., Guariento, S., Damonte, G., Cichero, E., et al. (2015). Synthesis and structure-activity relationship of aminoarylthiazole derivatives as correctors of the chloride transport defect in cystic fibrosis. Eur. J. Med. Chem. 99, 14-35. doi: 10.1016/j.ejmech.2015.05.030

Phuan, P. W., Veit, G., Tan, J. A., Finkbeiner, W. E., Lukacs, G. L., and Verkman, A. S. (2015). Potentiators of defective $\triangle$ F508-CFTR gating that do not interfere with corrector action. Mol. Pharmacol. 88, 791-799. doi: 10.1124/mol.115.099689

Phuan, P. W., Veite, G., Tan, J., Roldan, A., Finkbeiner, W. E., Lukacs, G. L., et al. (2014). Synergy-based small-molecule screen using a human lung epithelial cell line yields $\triangle$ F508-CFTR correctors that augment VX-809 maximal efficacy. Mol. Pharmacol. 86, 42-51. doi: 10.1124/mol.114.092478

Pibiri, I., Lentini, L., Melfi, R., Galluci, R., Pace, A., Spinello, A., et al. (2015). Enhancement of premature stop códon readthrough in the CFTR gene by ataluren (PTC124) derivatives. Eur. J. Med. Chem. 101, 236-244. doi: 10.1016/j.ejmech.2015.06.038

Pibiri, I., Lentini, L., Tutone, M., Melfi, R., Pace, A., and Di Leonardo, A. (2016). Exploring the readthrough of nonsense mutations by non-acidic ataluren analogues selected by ligand-based virtual screening. Eur. J. Med. Chem. 122, 429-435. doi: 10.1016/j.ejmech.2016.06.048

Pique, L., Graham, S., Pearl, M., Kharrazi, M., and Schrijver, I. (2016). Cystic fibrosis newborn screening programs: implications of the CFTR variant spectrum in nonwhite patients. Genet. Med. doi: 10.1038/gim.2016.48 [Epub ahead of print].

Plant, B. J., Goss, C. H., Plant, W. D., and Bell, S. C. (2013). Management of comorbidities in older patients with cystic fibrosis. Lancet Respir. Med. 1, 164-174. doi: 10.1016/S2213-2600(13)70025-0

Prayle, A., Watson, A., Fortnum, H., and Smyth, A. (2010). Side effects of aminoglycosides on the kidney, ear and balance in cystic fibrosis. Thorax 65, 654-658. doi: 10.1136/thx.2009.131532

Proteostasis Therapeutics. (2016). Proteostasis Therapeutics, Inc. Presents New Data Demonstrating Potential for Genotype-Agnostic and Combination Therapies for People with Cystic Fibrosis. Available at: http://ir.proteostasis.com/phoenix.zh tml? $\mathrm{c}=254052 \& p=$ irol-newsArticle $\& I D=2151856$ [accessed May 18, 2016].

Pyle, L. C., Fulton, J. C., Sloane, P. A., Backer, K., Mazur, M., Prasain, J., et al. (2010). Activation of cystic fibrosis transmembrane conductance regulator by the flavonoide quercetin: potential use as a biomarker of $\Delta \mathrm{F} 508$ cystic fibrosis transmembrane conductance regulator rescue. Am. J. Respir. Cell Mol. Biol. 43, 607-616. doi: 10.1165/rcmb. 2009-02810C

Quittner, A., Suthoff, E., Rendas-Baum, R., Bayliss, M. S., Sermet-Gaudelus, I., Castiglione, B., et al. (2015). Effect of ivacaftor treatment in patients with cystic fibrosis and the G551D-CFTR mutation: patient-reported outcomes in the STRIVE randomized, controlled trial. Health Qual. Life Outcomes 13, 93. doi: 10.1186/s12955-015-0293-6

Quon, B. S., and Rowe, S. M. (2016). New and emerging targeted therapies for cystic fibrosis. BMJ 352, i859. doi: 10.1136/bmj.i859

Rafferty, S., Alcolado, N., Norez, C., Chappe, F., Pelzer, S., Becq, F., et al. (2009). Rescue of functional F508del cystic fibrosis transmembrane conductance regulator by vasoactive intestinal peptide in the human nasal epithelial cell line JME/CF15. J. Pharmacol. Exp. Ther. 331, 2-13. doi: 10.1124/jpet.109. 155341

Ramsey, B. W., Davies, J., McElvaney, N. G., Tullis, E., Bell, S. C., Dřevínek, P., et al. (2011). A CFTR potentiator in patients with cystic fibrosis and the G551D mutation. N. Engl. J. Med. 365, 1663-1672. doi: 10.1056/NEJMoa 1105185
Rapino, D., Sabirzhanova, I., Lopes-Pacheco, M., Grover, R., Guggino, W. B., and Cebotaru, L. (2015). Rescue of NBD2 mutants N1303K and S1235R of CFTR by small-molecule correctors and transcomplementation. PLoS ONE 10:e0119796. doi: 10.1371/journal.pone.0119796

Riordan, J. R., Rommens, J. M., Kerem, B., Alon, N., Rozmahel, R., Grzelczak, Z., et al. (1989). Identification of the cystic fibrosis gene: cloning and characterization of complementary DNA. Science 245, 1066-1073. doi: 10.1126/science.2475911

Robert, R., Carlile, G. W., Pavel, C., Liu, N., Anjos, S. M., Liao, J., et al. (2008). Structural analog of sildenafil identified as a novel corrector of the F508del-CFTR trafficking defect. Mol. Pharmacol. 73, 478-489. doi: 10.1124/mol.107.040725

Ronan, N. J., Fleming, C., O'Callaghan, G., Maher, M. M., Murphy, D. M., and Plant, B. J. (2015). The role of ivacaftor in severe cystic fibrosis in a patient with the R117H mutation. Chest 148, e72-e75. doi: 10.1378/chest.14-3215

Roth, D. M., Hutt, D. M., Tong, J., Bouchecareih, M., Wang, N., Seeley, T., et al. (2014). Modulation of the maladaptive stress responde to manage diseases of protein folding. PLoS Biol. 12:e1001998. doi: 10.1371/journal.pbio. 1001998

Rowe, S. M., Borowitz, D. S., Burns, J. L., Clancy, J. P., Donaldson, S. H., Retsch-Bogart, G., et al. (2012). Progress in cystic fibrosis and the CF Therapeutics Development Network. Thorax 67, 882-890. doi: 10.1136/thoraxjnl-2012.202550

Rowe, S. M., Heltshe, S. L., Gonska, T., Donaldson, S. H., Borowitz, D., Gelfond, D., et al. (2014). Clinical mechanism of cystic fibrosis transmembrane conductance regulator potentiator ivacaftor in G551D-mediated cystic fibrosis. Am. J. Respir. Crit. Care Med. 190, 175-184. doi: 10.1164/rccm.201404-0703OC

Rowe, S. M., Sloane, P., Tang, L. P., Backer, K., Mazur, M., Buckley-Lanier, J., et al. (2011). Suppression of CFTR premature termination codons and rescue of CFTR protein and function by the synthetic aminoglycoside NB54. J. Mol. Med. 89, 1149-1161. doi: 10.1007/s00109-011-0787-6

Sabirzhanova, I., Lopes-Pacheco, M., Rapino, D., Grover, R., Handa, J. T., Guggino, W. B., et al. (2015). Rescuing trafficking mutants of the ATP-binding cassette protein, ABCA4, with small molecule correctors as a treatment for Stargardt eye disease. J. Biol. Chem. 290, 19743-19755. doi: 10.1074/jbc.M115.647685

Sampson, H. M., Lam, H., Chen, P. C., Zhang, D., Mottillo, C., Mirza, M., et al. (2013). Compounds that correct F508del-CFTR trafficking can also correct other protein trafficking diseases: an in vitro study using cell lines. Orphanet J. Rare Dis. 8, 11. doi: 10.1186/1750-1172-8-11

Sampson, H. M., Robert, R., Liao, J., Matthes, E., Carlile, G. W., Hanrahan, J. W., et al. (2011). Identification of a NBD1-binding pharmacological chaperone that corrects the trafficking defect of F508del-CFTR. Chem. Biol. 18, 231-242. doi: 10.1016/j.chembiol.2010.11.016

Sawicki, G. S., McKone, E. F., Pasta, D. J., Millar, S. J., Wagener, J. S., Johnson, C. A., et al. (2015). Sustained benefit from ivacaftor demonstrated by combining clinical trial and cystic fibrosis patient registry data. Am. J. Respir. Crit. Care Med. 192, 836-842. doi: 10.1164/rccm.201503-0578OC

Schrijver, I., Pique, L., Graham, S., Pearl, M., Cherry, A., and Kharrazi, M. (2016). The spectrum of CFTR variants in nonwhite cystic fibrosis patients: implication for molecular diagnostic testing. J. Mol. Diagn. 18, 39-50. doi: 10.1016/j.jmoldx.2015.07.005

Sermet-Gaudelus, I., Boeck, K. D., Casimir, G. J., Vermeulen, F., Leal, T., Mogenet, A., et al. (2010). Ataluren (PTC124) induces cystic fibrosis transmembrane conductance regulator protein expression and activity in children with nonsense mutation cystic fibrosis. Am. J. Respir. Crit. Care Med. 182, 1262-1272. doi: 10.1164/rccm.201001-0137OC

Serohijos, A. W., Hegedus, T., Aleksandrov, A. A., He, L., Cui, L., Dokhokyan, N. V., et al. (2008). Phynyalanine-508 mediates a cytoplasmic-membrane domain contact in the CFTR 3D structure crucial to assembly and channel function. Proc. Natl. Acad. Sci. U.S.A. 105, 3256-3261. doi: 10.1073/pnas.0800254105

Shah, V. S., Meyerholz, D. K., Tang, X. X., Reznikov, L., Abou Alaiwa, M., Ernst, S. E., et al. (2016). Airway acidification initiates host defense abnormalities in cystic fibrosis mice. Science 351, 503-507. doi: 10.1126/science.aadd5589

Sharma, M., Benharouga, M., Hu, W., and Lukacs, G. L. (2001). Conformational and temperature-sensitive satibility defects of the delta F508 cystic fibrosis transmembrane conductance regulator in post-endoplasmic reticulum compartments. J. Biol. Chem. 276, 8942-8950. doi: 10.1074/jbc.M009172200 
Sharma, M., Pampinella, F., Nemes, C., Benharouga, M., So, J., Du, K., et al. (2004). Misfolding diverts CFTR from recycling to degradation: quality controla t early endosomes. J. Cell Biol. 164, 923-933. doi: 10.1083/jcb.200312018

Sinha, C., Zhang, W., Moon, C. S., Actis, M., Yarlagadda, S., Arora, K., et al. (2015). Capturing the direct binding of CFTR correctors to CFTR by using click chemistry. Chembiochem 16, 2017-2022. doi: 10.1002/cbic.201500123

Smyth, A. R., Bell, S. C., Bojcin, S., Bryon, M., Duff, A., Flume, P., et al. (2014). European cystic fibrosis society standards of care: best practice guidelines. J. Cyst. Fibros. 13 (Suppl. 1), S23-S42. doi: 10.1016/j.jcf.2014.03.010

Sosnay, P. R., Siklosi, K. R., Van Goor, F., Kaniecki, K., Yu, H., Sharma, N., et al. (2013). Defining the disease liability of variants in the cystic fibrosis transmembrane conductance regulator gene. Nat. Genet. 45, 1160-1167. doi: 10.1038/ng.2745

Stanton, B. A., Coutermarsh, B., Barnaby, R., and Hogan, D. (2015). Pseudomonas aeruginosa reduces VX-809 stimulated F508del-CFTR chloride secretion by airway epithelial cells. PLoS ONE 10:e0127742. doi: 10.1371/journal.pone. 0127742

Stewart, C., and Pepper, M. S. (2016). Cystic fibrosis on the African continent. Genet. Med. 18, 653-662. doi: 10.1038/gim.2015.157

Suk, J. S., Kim, A. J., Trehan, K., Schneider, C. S., Cebotaru, L., Woodward, O. M., et al. (2014). Lung gene therapy with highly compacted DNA nanoparticles that overcome the mucus barrier. J. Control Release 178, 8-17. doi: 10.1016/j.jconrel.2014.01.007

Sun, F., Zhang, R., Gong, X., Geng, X., Drain, P. F., and Frizzell, R. A. (2006). Derlin-1 promotes the efficient degradation if the cystic fibrosis transmembrane conductance regulator (CFTR) and CFTR folding mutants. J. Biol. Chem. 281, 36856-36863. doi: 10.1074/jbc.M607085200

Swiatecka-Urban, A., Brown, A., Moreau-Marquis, S., Renuka, J., Coutermarsh, B., Barnaby, R., et al. (2005). The short apical membrane half-life of rescue \{Delta\}F508-cystic fibrosis transmembrane conductance regulator (CFTR) results from accelerated endocytosis of \{Delta\}F508-CFTR in polarized human airway epithelial cells. J. Biol. Chem. 280, 36762-36772. doi: 10.1074/jbc.M508944200

Tang, X. X., Ostedgaard, L. S., Hoegger, M. J., Moninger, T. O., Karp, P. H., McMenimen, J. D., et al. (2016). Acidic $\mathrm{pH}$ increases airway surface liquid viscosity in cystic fibrosis. J. Clin. Invest. 126, 879-891. doi: 10.1172/JCI83922

Tarran, R., Button, B., Picher, M., Paradiso, A. M., Ribeiro, C. M., Lazarowski, E. R., et al. (2005). Normal and cystic fibrosis airway surface liquid homeostasis. The effects of phasic shear stress and viral infections. J. Biol. Chem. 280, 35751-35759. doi: 10.1074/jbc.M505832200

Than, B. L., Linnekamp, J. F., Starr, T. K., Largaespada, D. A., Rod, A., Zhang, Y., et al. (2016). CFTR is a tumor suppressor gene in murine and human intestinal cancer. Oncogene 35, 4179-4187. doi: 10.1038/onc.2015.483

Tosco, A., De Gregorio, F., Esposito, S., De Stefano, D., Sana, I., Ferrari, E., et al. (2016). A novel treatment of cystic fibrosis acting on-target: cysteamine plus epigallocatechin gallate for the autophagy-dependent rescue of class II-mutated CFTR. Cell Death Differ. 23, 1380-1393. doi: 10.1038/cdd.2016.22

Van Goor, F., Hadida, S., Grootenhuis, P. D., Burton, B., Cao, D., Neuberger, T., et al. (2009). Rescue of CF airway cell function in vitro by a CFTR potentiator, VX-770. Proc. Natl. Acad. Sci. U.S.A. 106, 18825-18830. doi: 10.1073/pnas.0904709106

Van Goor, F., Hadida, S., Grootenhuis, P. D., Burton, B., Stack, J. H., Straley, K. S., et al. (2011). Correction of the F508del-CFTR protein processing defect in vitro by the investigational drug VX-809. Proc. Natl. Acad. Sci. U.S.A. 108, 18843-18848. doi: 10.1073/pnas.1105787108

Van Goor, F., Straley, K. S., Cao, D., González, J., Hadida, S., Hazlewood, A., et al. (2006). Rescue of deltaF508-CFTR trafficking and gating in human cystic fibrosis airway primary cultures by small molecules. Am. J. Physiol. Lung. Cell Mol. Physiol. 290, L1117-L1130. doi: 10.1152/ajplung.00169.2005

Van Goor, R., Yu, H., Burton, B., and Hoffman, B. J. (2014). Effect of ivacaftor on CFTR forms with missense mutations associated with defects in protein processing or function. J. Cyst. Fibros. 13, 29-36. doi: 10.1016/j.jcf.2013. 06.008

Vasiliou, V., Vasiliou, K., and Nebert, D. W. (2009). Human ATP-binding cassette (ABC) transporter family. Hum. Genomics 3, 281.290. doi: 10.1186/1479-73643-3-281

Veit, G., Avramescu, R. G., Chiang, A. N., Houch, S. A., Cai, Z., Peters, K. W., et al. (2016a). From CFTR biology toward combinatorial pharmacotherapy: expanded classification of cystic fibrosis mutations. Mol. Biol. Cell 27, 424-433. doi: 10.1091/mbc.E14-04-0935

Veit, G., Avramescu, R. G., Perdomo, D., Phuan, P. W., Dagdany, M., Apaja, P. M., et al. (2014). Some gating potentiators, including VX-770, diminish $\Delta$ F508-CFTR functional expression. Sci. Transl. Med. 6, 246ra97. doi: 10.1126/scitranslmed.3008889

Veit, G., Oliver, K., Apaja, P. M., Perdomo, D., Bidaud-Meynard, A., Lin, S. T., et al. (2016b). Ribosomal stalk protein silencing partially corrects the $\triangle$ F508-CFTR functional expression defect. PLoS Biol. 14:e1002462. doi: 10.1371/journal.pbio.1002462

Vertex Pharmaceuticals (2015). Vertex Announces Significant Progress in Its Development Efforts to Treat the Cause of Cystic Fibrosis in the Vast Majority of People with the Disease. Available at: http://investors.vrtx.com/releasedetail.c $\mathrm{fm}$ ?ReleaseID $=935806$ [accessed May 18, 2016].

Vij, N., Fang, S., and Zeitlin, P. L. (2006). Selective inhibition of endoplasmic reticulum-associated degradation rescues deltaF508-cystic fibrosis transmembrane regulator and suppresses interleukin-8 levels: therapeutic implications. J. Biol. Chem. 281, 17369-17378. doi: 10.1074/jbc.M600509200

Vij, N., Min, T., Marasigan, R., Belcher, C. N., Mazur, S., Ding, H., et al. (2010). Development of PEGylated PLGA nanoparticle for controlled and sustained drug delivery in cystic fibrosis. J. Nanobiotechnology 8, 22. doi: 10.1186/14773155-8-22

Vijftigschild, L. A., Berkers, G., Dekkers, J. F., Zomer-van Ommen, D. D., Matthes, E., Kruisselbrink, E., et al. (2016). $\beta 2$-Adrenergic receptor agonists activate CFTR in intestinal organoids and subjects with cystic fibrosis. Eur. Respir. J. doi: 10.1183/13993003.01661-2015 [Epub ahead of print].

Villella, V. R., Esposito, S., Bruscia, E. M., Vicinanza, M., Cenci, S., Guido, S., et al. (2013). Disease relevant proteostasis regulation of cystic fibrosis transmembrane conductance regulator. Cell Death. Differ. 80, 1101-1115. doi: $10.1038 / \mathrm{cdd} .2013 .46$

Vu, V., Verster, A. J., Schertzberg, M., Chuluunbaatar, T., Spensley, M., Pajkic, D., et al. (2015). Natural variation in gene expression modulates the severity of mutant phenotypes. Cell 162, 391-402. doi: 10.1016/j.cell.2015.06.037

Wainwright, C. E., Elborn, J. S., Ramsey, B. W., Marigowda, G., Huang, X., Cipolli, M., et al. (2015). Lumacaftor-Ivacaftor in patients with cystic fibrosis homozygous for phe508del CFTR. N. Engl. J. Med. 373, 220-231. doi: 10.1056/NEJMoa1409547

Wang, X., Venable, J., LaPointe, P., Hutt, D. M., Koulov, A. V., Coppinger, J., et al. (2006). Hsp90 cochaperone Ahal downregulation rescues misfolding of CFTR in cystic fibrosis. Cell 127, 803-812. doi: 10.1016/j.cell.2006. 09.043

Wang, Y., Loo, T. W., Bartlett, M. C., and Clarke, D. M. (2007a). Correctors promote maturation of cystic fibrosis transmembrane conductance regulator (CFTR)-processing mutants by binding to the protein. J. Biol. Chem. 282, 33247-33251. doi: 10.1074/jbc.C700175200

Wang, Y., Loo, T. W., Bartlett, M. C., and Clarke, D. M. (2007b). Modulating the folding of P-glycoprotein and cystic fibrosis transmembrane conductance regulator truncation mutants with pharmacological chaperones. Mol. Pharmacol. 71, 751-758. doi: 10.1124/mol.106.029926

Wilschanski, M., Miller, L. L., Shoseyov, D., Blau, H., Rivlin, J., Aviram, M., et al. (2011). Chronic ataluren (PTC124) treatment of nonsense mutation cystic fibrosis. Eur. Respir. J. 38, 59-69. doi: 10.1183/09031936.00120910

Wilschanski, M., Yahav, Y., Yaacov, Y., Blau, H., Bentur, L., Rivlin, J., et al. (2003). Gentamicin-induced correction of CFTR function in patients with cystic fibrosis and CFTR stop mutations. N. Engl. J. Med. 349, 1433-1441. doi: 10.1056/NEJMoa022170

Winter, M. C., and Welsh, M. J. (1997). Stimulation of CFTR activity by its phosphorylated R domain. Nature 389, 294-296. doi: 10.1038/ 38514

Woodward, O. M., Tukayne, D. N., Cui, J., Greenwell, P., Constantoulakis, L. M., and Parker, B. S. (2013). Gout-causing Q141K mutation in ABCG2 leads to instability of the nucleotide-binding domain and can be corrected with small molecules. Proc. Natl. Acad. Sci. U.S.A. 110, 5223-5228. doi: 10.1073/pnas. 1214530110

Worlitzsch, D., Tarran, R., Ulrich, M., Schwab, U., Cekici, A., Meyer, K. C., et al. (2002). Effects of reduced mucus oxygen concentration in airway Pseudomonas infections of cystic fibrosis patients. J. Clin. Invest. 109, 317-325. doi: 10.1172/JCI13870 
Xue, X., Mutyam, V., Tang, L., Biswas, S., Du, M., Jackson, L. A., et al. (2014). Synthetic aminoglycosides efficiently suppress cystic fibrosis transmembrane conductance regulator nonsense mutations and are enhanced by ivacaftor. Am. J. Respir. Cell Mol. Biol. 50, 805-816. doi: 10.1165/rcmb.2013$0282 \mathrm{OC}$

Yang, Y., Janich, S., Cohn, J. A., and Wilson, J. M. (1993). The common variant of cystic fibrosis transmembrane conductance regulator is recognized by hsp70 and degraded in a pre-Golgi nonlysosomal compartment. Proc. Natl. Acad. Sci. U.S.A. 90, 9480-9484. doi: 10.1073/pnas.30.20.9480

Yu, H., Burton, B., Huang, C. J., Worley, J., Cao, D., Johnson, J. P. Jr., et al. (2012). Ivacaftor potentiation of multiple CFTR channels with gating mutations. J. Cyst. Fibros. 11, 237-245. doi: 10.1016/j.jcf.2011.12.005

Yu, Y. C., Miki, H., Nakamura, Y., Hanyuda, A., Matsuzaki, Y., Abe, Y., et al. (2011). Curcumin and genistein additively potentiate G551D-CFTR. J. Cystc. Fibros. 10, 243-252. doi: 10.1016/j.jcf.2011.03.001

Yu, Y. C., Sohma, Y., and Hwang, T. C. (2016). On the mechanism of gating defects caused by the R117H mutation in CFTR. J. Physiol. 594, 3227-3244. doi: 10.1113/JP271723

Yuan, S., Hollinger, M., Lachowicz-Scroggins, M. E., Kerr, S. C., Dunican, E. M., Daniel, B. M., et al. (2015). Oxidation increases mucin polymer cross-links to stiffen airway mucus gels. Sic. Transl. Med. 7, 276ra27. doi: 10.1126/scitranslmed.3010525

Zaman, K., Sawczak, V., Zaidi, A., Butler, M., Bennett, D., and Getsy, P. (2016). Augmentation of CFTR maturation by S-nitroglutathione reductase. Am. J. Physiol. Lung Cell. Mol. Physiol. 310, L263-L270. doi: 10.1152/ajplung.00269.2014
Zhang, D., Ciciriello, F., Anjos, S. M., Carissimo, A., Liao, J., Carlile, G. W., et al. (2012). Ouabain mimics low temperature rescue of F508del-CFTR in cystic fibrosis epithelial cells. Front. Pharmacol. 3:176. doi: 10.3389/fphar.2012.00176

Zhou, Y., Jiang, Q., Takahagi, S., Shao, C., and Uitto, J. (2013). Premature termination codon read-through in the ABCC6 gene: potential treatment for pseudoxanthoma elasticum. J. Invest. Dermatol. 133, 2672-2677. doi: 10.1038/jid.2013.234

Zomer-van Ommen, D. D., Vijftigschild, L. A., Kruisselbrink, E., Vonk, A. M., Dekkers, J. F., Janssens, H. M., et al. (2016). Limited premature termination codon suppression by read-through agents in cystic fibrosis intestinal organoids. J. Cyst. Fibros. 15, 158-162. doi: 10.1016/j.jcf.2015.07.007

Zucker, D. R., Ruthazer, R., and Schmid, C. H. (2010). Individual (N-of-1) trials can be combined to give population comparative treatment effect es: methodologic considerations. J. Clin. Epidemiol. 63, 1312-1323. doi: 10.1016/j.jclinepi.2010.04.020

Conflict of Interest Statement: The author declares that the research was conducted in the absence of any commercial or financial relationships that could be construed as a potential conflict of interest.

Copyright (c) 2016 Lopes-Pacheco. This is an open-access article distributed under the terms of the Creative Commons Attribution License (CC BY). The use, distribution or reproduction in other forums is permitted, provided the original author(s) or licensor are credited and that the original publication in this journal is cited, in accordance with accepted academic practice. No use, distribution or reproduction is permitted which does not comply with these terms. 